\title{
DENISE TAFFARELLO
}

\section{EXTRATOS DE ARRABIDAEA CHICA (HUMB. \& BONPL.)}

VERLOT OBTIDOS POR PROCESSOS BIOTECNOLÓGICOS:

\section{OTIMIZAÇÃO DA EXTRAÇÃo E AVALIAÇÃO FARMACOLÓGICA}

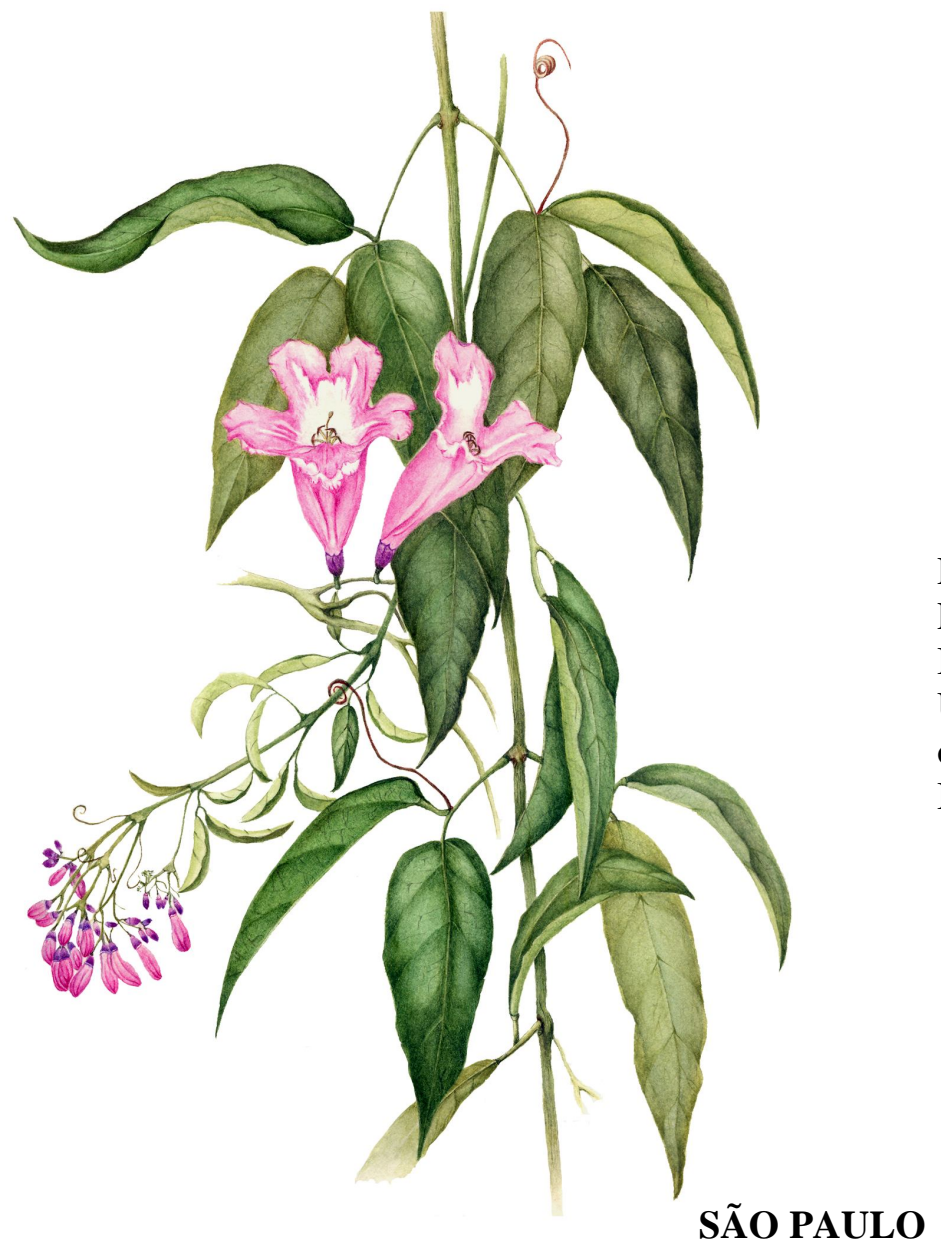

Dissertação apresentada ao Programa de Pós Graduação Interunidades em Biotecnologia USP/Instituto Butantan/IPT, para obtenção do Título de Mestre em Biotecnologia. 


\title{
DENISE TAFFARELLO
}

\section{EXTRATOS DE ARRABIDAEA CHICA (HUMB. \& BONPL.) VERLOT OBTIDOS POR PROCESSOS BIOTECNOLÓGICOS: OTIMIZAÇÃO DA EXTRAÇÃO E AVALIAÇÃO FARMACOLÓGICA}

\author{
Dissertação apresentada ao \\ Programa de Pós Graduação \\ Interunidades em Biotecnologia \\ USP/Instituto Butantan/IPT, para \\ obtenção do Título de Mestre em \\ Biotecnologia. \\ Área de concentração: \\ Biotecnologia \\ Orientador: \\ Profa. Dra. Mary Ann Foglio
}




\section{RESUMO}

TAFFARELlO, D. Extratos de Arrabidaea chica (Humb. \& Bonpl.) Verlot obtidos por processos biotecnológicos: otimização da extração e avaliação farmacológica. 2008. 191 f. Dissertação (Mestrado em Biotecnologia) - Instituto de Ciências Biomédicas, Universidade de São Paulo, São Paulo, 2009.

A Arrabiadaea chica (Humb. \& Bonpl.) Verlot (Bignoniaceae), popularmente conhecida como Crajiru, é uma liana lenhosa, que possui folhas que fornecem pigmentos vermelhos, carajurina e carajurona, utilizados pelos índios brasileiros como corante e agente cicatrizante. $\mathrm{O}$ presente estudo visou otimizar a extração de compostos fenólicos de A. chica, através de processos biotecnológicos, e avaliar seus efeitos anticancerígeno, cicatrizante e antioxidante. Extratos metanólicos de A. chica foram obtidos através de tratamento com xilanases de Bacillus pumilus previamente à extração, sendo que o tempo ótimo de incubação enzimática foi determinado como duas horas. O conteúdo de pigmentos foi monitorado por cromatografia líquida de alta eficiência e o teor de pigmentos nos extratos obtidos sem e com tratamento enzimático a partir de folhas de $A$. chica coletadas mensalmente em 2007 foi obtido por espectrometria de massas por electronspray. Extratos produzidos com xilanases que apresentaram maior teor de pigmentos em relação à biomassa foram obtidos a partir de folhas coletadas em março e setembro, indicando que o ritmo circadiano influencia a produção de antocianinas. O tratamento enzimático forneceu extratos enriquecidos em antocianidinas (carajurina $\mathrm{m} / \mathrm{z} 299$ ), enquanto que os extratos obtidos sem tratamento enzimático apresentaram maior teor de antocianosídeos (compostos glicosilados $\mathrm{m} / \mathrm{z}$ 463 e $\mathrm{m} / \mathrm{z}$ 477), evidenciando que as xilanases promoveram hidrólise enzimática, liberando as agliconas. $\mathrm{O}$ estudo farmacológico demonstrou que a atividade anticâncer e antioxidante in vitro de A. chica estão diretamente relacionadas ao maior teor de agliconas liberado pelo tratamento com xilanases. Por outro lado, o ensaio in vitro de indução de crescimento de fibroblastos demonstrou que o maior teor da aglicona carajurina é inversamente proporcional à ação cicatrizante. Extratos obtidos sem tratamento enzimático apresentaram maior ação cicatrizante $\left(\mathrm{CE}_{50} 35 \mu \mathrm{g} / \mathrm{mL}\right)$ do que aqueles obtidos com o tratamento. Portanto, foi desenvolvido um novo processo de extração biotecnológico que permite a produção de aglicona livre com propriedade corante e atividades anticâncer e antioxidante in vitro.

Palavras-chave: Arrabidaea chica; Bacillus pumilus; extração de corante; anticâncer; cicatrização; capacidade antioxidante. 


\begin{abstract}
TAFFARELlO, D. Arrabidaea chica (Humb. \& Bonpl.) Verlot extracts obtained by biotechnological processes: extraction optimization and pharmacological evaluation. 2008. $191 \mathrm{f}$. Dissertação (Mestrado em Biotecnologia) - Instituto de Ciências Biomédicas, Universidade de São Paulo, São Paulo, 2009.
\end{abstract}

Arrabiadaea chica (Humb. \& Bonpl.) Verlot (Bignoniaceae), popularly known as Crajiru, is a vine with leaves containing red pigments, carajurin and carajuron, used by Brazilian indian populations as dye and healing agent. This study aimed the production of optimized phenolic compounds extracts from A. chica, by biotechnological processes, and evaluation of anticancer, healing and antioxidant effects. Methanolic extracts from A. chica were obtained by previously treating leaves with xylanases obtained from Bacillus pumilus. The optimum enzymatic incubation time was determined as two hours. The pigment content was monitored by high pressure liquid chromatography and the amounts of pigments obtained in extracts, with or without enzymatic treatment of A. chica collected monthly during 2007 were obtained by mass spectrometry "electronspray". The extracts produced by previous xylanases treatment presented higher pigment content. The best pigment versus biomass, were obtained from the leaves collected on March and September, indicating that the circadian rhythm plays an important influence on the anthocyanin content production. The enzymatic treatment produced extracts with higher aglycone content (carajurin $\mathrm{m} / \mathrm{z}$ 299), whereas the extracts without previous enzymatic treatment showed higher anthocyanoside content (glycosilated compounds m/z 463 and m/z 477). That observation proved that the xylanases promoted the enzymatic hydrolysis, releasing the aglycones. The pharmacologic study demonstrated the in vitro antitumor and antioxidant properties of $A$. chica have a straight relationship with higher aglycone content. On the other hand, in vitro assays for fibroblasts growth induction demonstrated that a higher content carajurin aglycone has an inverse relationship with healing properties. Sample extracts obtained without previous enzymatic treatment presented better healing action $\left(\mathrm{CE}_{50} 35 \mu \mathrm{g} / \mathrm{mL}\right)$ than those obtained with previous enzymatic treatment. Therefore a novel biotechnological extraction process was developed that permits the production of free aglycone with dye property and in vitro anticancer and antioxidant activities.

Key words: Arrabidaea chica; Bacillus pumilus; dye extraction; anticancer; healing; antioxidant capacity. 


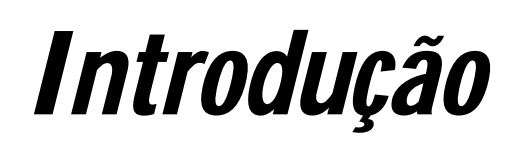




\section{INTRODUÇÃO}

\subsection{BIOTECNOLOGIA}

\subsubsection{Histórico}

Cultivar vegetais, domesticar animais, transformar os alimentos ou aproveitar as propriedades curativas de algumas plantas são atividades que se perdem na história da humanidade e se desenvolveram com base no conhecimento empírico, ignorando a existência dos microorganismos (MALAJOVICH, 2004).

A atividade agrária gerou excesso de produção, que impulsionou o desenvolvimento de técnicas de conservação dos alimentos. Somou-se a necessidade de diversificação dos produtos finais obtidos pelo homem essencialmente agrário. Assim, surgiram os primeiros alimentos e bebidas produzidos por fermentação: vinho, cerveja, pão e queijo. Apesar da simplicidade das técnicas utilizadas, essa atividade pode ser considerada o embrião da biotecnologia (FERNANDES, 2008).

Somente a partir do século XIX a biotecnologia transformou-se em ciência aplicada à produção industrial. A capacidade dos microorganismos de realizarem a fermentação foi demonstrada, entre 1857 e 1876, por Louis Pasteur, considerado o pai da biotecnologia (SMITH, 2004). Em 1897, Eduard Buchner demonstrou que a fermentação do açúcar em álcool é promovida por moléculas que continuavam funcionando, após serem removidas das leveduras. Frederick W. Kühne denominou tais moléculas de enzimas (LEHNINGER et al., 2005). Deve-se a Ereky, em 1919, a primeira definição de biotecnologia como "a ciência e os métodos que permitem a obtenção de produtos a partir da matéria-prima, mediante a intervenção de organismos vivos". Para ele, a era da bioquímica substituiria a era da pedra e do ferro (MALAJOVICH, 2004).

Entretanto, os maiores avanços da biotecnologia ocorreram a partir do século XX. A descoberta dos antibióticos em 1929 e sua subseqüente produção em larga escala na década de 40 trouxe grandes avanços na tecnologia das fermentações (SMITH, 2004). Posteriormente, a descoberta da estrutura do DNA por Francis Crick e James Watson, publicada, em 1953, na revista Nature constituiu importante marco na biotecnologia

\section{DeniseTaffarello}


moderna. A tecnologia do DNA recombinante de Cohen e Boyer possibilitou, em 1978, gerar o primeiro produto biotecnológico comercial, a insulina humana expressada em Escherichia coli. Este desenvolvimento levou à inauguração da primeira companhia biotecnológica, a "Genentech", em 1980 (KNÄBLEIN, 2007). Outro grande avanço se deu a partir de 1990, com o lançamento do "Projeto Genoma Humano" (PGH), cuja previsão de conclusão era para o ano de 2005, mas foi concluído em 2001, com publicações simultâneas nas revistas Nature e Science por dois dos grupos de pesquisas envolvidos. Ressalta-se que desde o princípio o PGH enfatizou a importância do desenvolvimento de novas tecnologias (MIR et al., 2004).

Segundo Valle e Assad (2007), a inovação em biotecnologia no Brasil apresenta forte proeminência do setor público, baixo nível de investimento em pesquisa e desenvolvimento por empresas privadas, cultura empresarial pouco afeita a riscos e cenário político difuso no tocante a aspectos regulatórios. A despeito desta conjuntura, a biotecnologia no Brasil respondeu por cerca de 2,8\% do Produto Interno Bruto (PIB) no ano 2000 e até 2004 efetuou transações da ordem de US\$ 500 milhões. A contribuição do setor público foi estrutural para viabilizar a evolução da biotecnologia no país. A instituição do Programa Genoma pela Fundação de Amparo à Pesquisa do Estado de São Paulo (FAPESP) em 1997, visando desenvolver competências em genômica, representou um ponto de inflexão fundamental. Neste programa, destacou-se o seqüenciamento da Xylella fastidiosa ${ }^{1}$, que possibilitou a criação, em 2002, de uma empresa brasileira de pesquisa e desenvolvimento na área de biotecnologia vegetal, constituída por capital 100\% nacional, a Alellyx (VALLE e ASSAD, 2007; SILVA, 2006).

A utilização de biotecnologias inovadoras tem contribuído para o aumento da qualidade de vida e gerado novos caminhos para o desenvolvimento econômico. O governo brasileiro divulgou, em 04 de julho de 2006, a "Estratégia Nacional de Biotecnologia - Política de desenvolvimento da bioindústria”, a qual prevê investimentos de sete bilhões de reais dos setores público e privado em biotecnologia. Outro fato marcante que incentivou o investimento em produtos e processos biotecnológicos no Brasil foi o decreto $\mathrm{n}^{\circ}$ 6.041, de 8 de fevereiro de 2007, que, dentre outras providências, instituiu a "Política de Desenvolvimento da Biotecnologia." Esta destaca como uma de suas prioridades a área de Fitoquímica que, associada à Genômica e à Proteômica, deve apoiar a

\footnotetext{
${ }^{1}$ Bactéria fitopatogênica causadora da clorose variegada em cultura de citros.
} 
constituição de redes de bioprospecção da biodiversidade nativa (Diário Oficial da União, 08/02/2007).

No início do século XXI surgiram novas técnicas biotecnológicas, como a biossíntese combinatória, a proteômica clínica e a metabolômica. Estas devem permitir a compreensão do real potencial das plantas para a humanidade. $\mathrm{Na}$ alvorada deste novo milênio, esforços para o desenvolvimento de novas ferramentas biotecnológicas podem resultar na produção de grandes quantidades de biofármacos, suficientes e necessárias para tratar toda a população do nosso planeta (VERPOORTE et al., 2005; VERPOORTE et al., 2007).

\subsection{APLICAÇÕES INDUSTRIAIS DE XILANASES}

Os catalisadores das reações químicas dos sistemas biológicos são as enzimas, proteínas altamente especializadas. Elas possuem elevado poder catalítico freqüentemente maior do que o dos catalisadores inorgânicos. Sua importância deve-se à capacidade de, a partir de simples precursores, formarem macromoléculas biológicas essenciais na constituição dos organismos. Através da ação de enzimas reguladoras, as vias metabólicas são integradas produzindo uma interação harmoniosa entre as diversas atividades imprescindíveis à vida. Desde o final do século $\mathrm{XX}$, pesquisas sobre enzimas têm sido intensificadas, levando à purificação, elucidação da estrutura e do mecanismo químico de diversos catalisadores biológicos (LEHNINGER et al., 2005). Recentemente, algumas enzimas têm sido empregadas em aplicações biotecnológicas.

O conhecimento de microorganismos que apresentam atividade lignocelulolítica ${ }^{2}$ é importante para a compreensão da reciclagem de biomassa vegetal na natureza, e também para a utilização de enzimas ou microorganismos em conversões de lignocelulose controladas. As enzimas envolvidas na degradação de lignocelulose, tais como xilanases, $\beta$-glicosidases e celulases têm sido empregadas em aplicações biotecnológicas como alternativa aos tratamentos químicos ou para aumentar a eficiência destes (LOPEZ et al., 2007; WEI et al., 2008). Como exemplo, pode ser citado o emprego de xilanases (1,4- $\beta$-Dxilano xilanoidrolase) na indústria de papel e celulose, para facilitar a extração da lignina,

\footnotetext{
${ }^{2}$ Ligninocelulose: polissacarídeo presente na parede celular vegetal.
}

\section{DeniseTaffarello}


reduzindo o consumo de compostos químicos tóxicos utilizados no branqueamento da polpa $^{3}$ (DUARTE et al., 2003; KOLENOVÁ et al., 2006).

A fermentação microbiana tem sido extensivamente aplicada para obtenção de corantes naturais, incluindo o desenvolvimento de linhagens geneticamente modificadas. Foram relatados a produção do apocarotenóide bixina em Escherichia coli e o desenvolvimento de novas rotas biossintéticas para a produção de flavonóides simples e incolores em sistemas microbianos (DAVIES, 2004). A degradação enzimática do resíduo agrícola pode fornecer fonte de carbono em fermentações industriais para produzir combustíveis alternativos e outros compostos (KOLENOVÁ et al., 2006).

A hidrólise da xilana, o maior polissacarídeo hemicelulósico presente na parede celular vegetal, é importante em várias aplicações biotecnológicas (POORNA e PREMA, 2006; KOLENOVÁ et al., 2006; LI et al., 2007). Enzimas xilanolíticas otimizam processos fermentativos, atuam no cozimento, além de serem empregadas na indústria de papel e celulose (KOLENOVÁ et al., 2006). Foi relatado o vantajoso emprego de xilanases para a melhoria da digestão animal, quando suplementada na dieta suína e avícola, na indústria alimentícia, na técnica das fermentações, no tratamento de resíduo agrícola, na indústria farmacêutica (POORNA e PREMA, 2006; LI et al.,2007). Muitas dessas aplicações não requerem xilanases purificadas, e a presença de celulases e/ou pectinases é freqüentemente desejável.

Também há interesse na produção de xilose, xilobiose e xilooligômeros. Diversos trabalhos citam que tais açúcares podem ser preparados por hidrólise enzimática da xilana, enquanto outros açúcares podem ser adicionados usando a atividade de enzimas de transglicolação, tais como $\beta$-xilosidase. Os xilooligossacarídeos possuem propriedades benéficas à saúde. Exibem atividades prebióticas por facilitarem o crescimento de Bifidobacterium sp. no trato gastrointestinal. Foi demonstrado que xilooligossacarídeos reduzem o risco de câncer de cólon em camundongos (HSU et al., 2004). Ademais, podem ser utilizados como ingredientes em alimentos, cosméticos, medicamentos ou produtos agrícolas, por conta de suas atividades biológicas. Foi relatado o emprego de

${ }^{3}$ Fibra de madeira moída para a produção do papel.

\section{DeniseTaffardlo}


xilooligossacarídeos funcionando como reguladores de crescimento em plantas, biorreguladores de aclimatização e agentes antibacterianos (KOLENOVÁ et al., 2006).

Xilanases microbianas são mais vantajosas, em relação às obtidas de fontes vegetais e animais, devido a sua maior disponibilidade, estabilidade estrutural e fácil manipulação genética (POORNA e PREMA, 2006). Particularmente, fungos filamentosos foram reportados como secretores de uma variada gama destas enzimas (LI et al., 2006).

\subsection{IMPORTÂNCIA DE PLANTAS MEDICINAIS}

A utilização de plantas com finalidades medicamentosas é milenar. Desde a antigüidade as plantas vêm sendo utilizadas pela humananidade com propósitos terapêticos, sendo que suas propriedades tóxicas ou curativas foram descobertas pelo homem principalmente enquanto este buscava por alimento (MARASCHI \& VERPOORTE, 1999).

O hábito de recorrer à cura através do uso de plantas medicinais persiste. Segundo Walsh (2003), cerca de três bilhões de pessoas em todo o mundo ainda utilizavam produtos obtidos de plantas medicinais como forma primária de tratamento para doenças. De acordo com Valle e Assad (2007), o conhecimento tradicional é de particular importância para a biotecnologia, dado que dos 120 princípios ativos isolados de plantas utilizados na medicina moderna, $75 \%$ foram identificados como originados a partir do uso popular.

A análise do índice de novos fármacos aprovados para uso terapêutico entre os anos 2000 e 2006 demonstrou que cerca de 50\% destes são originários de produtos naturais. Neste período, o fármaco mais vendido no mundo foi a atorvastatina, um hipocolesterolêmico originário do fungo filamentoso Monascus ruber, cujas vendas, em 2004, renderam mais de 11 bilhões de dólares e continuam neste ou acima deste valor até hoje (NEWMAN e CRAGG, 2007). Estima-se que mais de 50\% dos medicamentos prescritos nos Estados Unidos devam conter princípios ativos de origem natural, sendo que pelo menos $25 \%$ contêm substâncias ativas isoladas de plantas, ou são formas modificadas dos compostos químicos isolados (KINGHORN, 2001; BALUNAS e KINGHORN, 2005).

\section{DeniseTaffarello}


Fitoterápicos são responsáveis por $25 \%$ do receituário médico nos países desenvolvidos e cerca de $80 \%$ nos países em desenvolvimento (SIMÕES et al., 2007).

Segundo Walsh (2003), um marco no desenvolvimento da indústria farmacêutica foi a descoberta e síntese química da sulfa, grupo de moléculas derivadas de um corante vermelho que eram efetivas no tratamento das infecções bacterianas. A partir de 1941, com a produção em escala industrial da penilicina, antibiótico natural derivado do fungo Penicillium chrysogenum ou $P$. notatum, o desenvolvimento da indústria farmacêutica foi acelerado. Desde então, grandes companhias farmacêuticas desenvolveram tetraciclinas, corticosteróides, anticoagulantes, estimulantes do sistema nervoso central, entre outros, a partir de plantas medicinais (Tabela 1).

Tabela 1: Alguns fármacos produzidos a partir de plantas medicinais

\begin{tabular}{cccc}
\hline Fármaco & Classe & Indicação & Planta produtora \\
\hline Aspirina & Salicilato & Analgésico, anti-inflamatório & Salix alba \\
Atropina & Alcalóide & Dilatador das pupilas & Atropa belladonna \\
Cafeína & Alcalóide & Estimulante do SNC & Cammelia sinensis \\
Cocaína & Alcalóide & Anestésico oftálmico & Erytoxylum coca \\
Codeína & Alcalóide & Analgésico, contra tosse & Papaver \\
Dicumarol & Cumarina & Anticoagulante & Melilotus officinalis \\
Digoxina & Esteróide & $\uparrow$ Contrações musc. cardíaco & Digitalis purpurea \\
Morfina & Alcalóide & Analgésico & Papaver \\
Pseudoefedrina & Alcalóide & Alívio da congestão nasal & Ephedra sinica \\
Quinina & Alcalóide & Malária & Cinchona pubescens \\
Reserpina & Alcalóide & Anti-hipertensivo & Rauvolfia \\
Escopolamina & Alcalóide & Antiespasmódico & Datura stramonium \\
Taxol & Terpenóide & Câncer de mama, de ovário & Taxus brevifolia \\
Teofilina & Alcalóide & Diurético & Cammelia sinensis \\
Vimblastina & Alcalóide & Doença de Hodgkin & Catharanthus \\
Vincristina & Alcalóide & Leucemia & Catharanthus \\
\hline
\end{tabular}

FONTE: modificado de Walsh, 2003.

A grande eficácia clínica de substâncias antitumorais obtidas de plantas tem contribuído para o aumento do interesse em pesquisas com plantas medicinais. Alguns compostos anticancerígenos, cujos exemplos clássicos são os alcalóides vimblastina e 
vincristina (Fig.1), isolados de Cataranthus roseus (Apocynaceae) (BALUNAS e KINGHORN, 2005) e, mais recentemente, o taxol, alcançam preços elevados no mercado mundial, evidenciando o potencial econômico que uma espécie medicinal pode ter. Alguns estudos revelaram novos princípios ativos vegetais com atividade antiproliferativa, tais como substâncias isoladas da Cephalotaxus harringtonia e de espécies da família Apocynaceae, que têm apresentado eficácia contra leucemias e câncer de mama, respectivamente (CRAGG, 1999; NEWMAN e CRAGG, 2007).

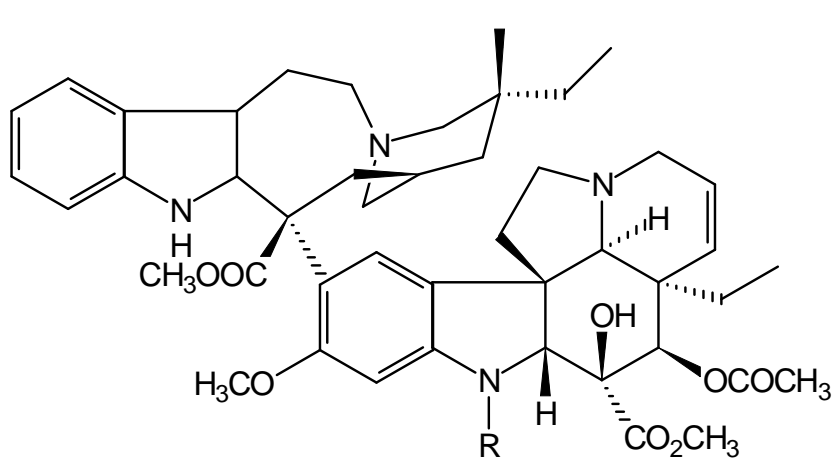

$\mathrm{R}=\mathrm{CH}_{3}:$ vimblastina

$\mathrm{R}=\mathrm{CHO}$ : vincristina

Figura 1: Estruturas químicas dos alcalóides vimblastina e vincristina.

Outro aspecto importante é a obtenção de compostos que, apesar de apresentarem potencial terapêutico limitado, podem ser utilizados como matéria-prima inicial para a obtenção de produtos semi-sintéticos com atividade farmacológica mais pronunciada. Como exemplo podem ser citados o desenvolvimento do atracúrio a partir dos alcalóides do curare, obtidos de Chondrodendron tometosum, dos anestésicos locais desenvolvidos a partir da cocaína, Erytoxylum coca (BUSS e WAIGH, 1995), e do potente antimalárico artesunato de sódio, produzido por semi-síntese a partir da artemisinina, isolado da Artemisia annua.(FOGLIO, 1996).

Recentemente, a biotecnologia permitiu o desenvolvimento de novos fármacos, especialmente para o tratamento de diabetes dos tipos I e II. Estes incluem vários compostos biológicos desenvolvidos com base na modificação da molécula de insulina, produzida por processos biotecnológicos (NEWMAN e CRAGG, 2007). Apesar das plantas serem promissoras para a descoberta de novas moléculas de interesse farmacológico, estimativas revelam que apenas $17 \%$ delas já foram estudadas quanto ao seu potencial medicinal. Assim, a biodiversidade representa um imenso potencial de 
utilização econômica pela biotecnologia (CRAGG et al., 1999; CRAGG e NEWMAN, 2005; NEWMAN e CRAGG, 2007; NEWMAN, 2008), justificando esforços para sua conservação.

O Brasil é o país com a maior biodiversidade vegetal do mundo, contando com mais de 55.000 espécies de plantas catalogadas, de um total estimado entre 350.000 e 550.000 (SIMÕES et al., 2007). As plantas do cerrado e das florestas equatoriais e tropicais brasileiras estão submetidos à devastação progressiva, causada pela exploração de seus recursos e avanço das fronteiras agropecuárias (DELITTI, 2008). Tal processo resulta em enorme perda de biodiversidade. Segundo Kinghorn (2001), ainda mais grave é a perda da sabedoria humana acumulada por milhares de anos, isto é, o conhecimento sobre como utilizar a floresta sem destruí-la, em benefício da própria saúde, está desaparecendo. Nos trópicos, diversas espécies estão ameaçadas de extinção, porém o conhecimento tradicional associado a elas está desaparecendo a uma taxa ainda mais veloz.

O contexto científico brasileiro na área de química de produtos naturais tem recebido investimentos por parte da iniciativa privada e, sobretudo, do governo. Entretanto, a magnitude dos estudos químicos e biológicos com espécies nativas está muito aquém do desejado. A continuidade e diversificação de iniciativas e investimentos na bioprospecção dos ativos da biodiversidade vegetal brasileira constituem-se em instrumento indispensável para que haja utilização sustentável dos diferentes ecossistemas encontrados no território nacional, permitindo a renovação dos recursos naturais para as próximas gerações (BENEVIDES, 2001), além de permitir o avanço científico do país, diminuindo a dependência externa na produção de fármacos.

Por outro lado, a utilização de plantas medicinais está sujeita a alguns problemas, frutos da desinformação, que ocorrem em função da comercialização de material sem controle, tanto na qualidade como na validade. Dúvidas quanto à procedência e a legitimação da espécie vendida são constantes. Os nomes populares confundem tanto os consumidores como os vendedores, pois variam de uma região para outra. Desta forma, a análise química dos extratos de plantas medicinais através de técnicas instrumentais rápidas, de alta precisão, exatidão e versatilidade torna-se indispensável à certificação de origem, ao controle de qualidade do produto e do processo, assim como na avaliação de contaminações ou degradações, comuns em amostras vegetais (SILVA et al., 2006).

\section{DeniseTaffarelo}


Além destes estudos de identificação, adulterações e contaminações há a necessidade de uma análise química detalhada de plantas destinadas ao uso terapêutico devido aos inúmeros fatores que podem levar a variações no conteúdo dos metabólitos secundários em plantas (Fig. 2). O controle de qualidade rigoroso realizado por meio de técnicas analíticas modernas, como a espectrometria de massas, faz-se necessário para avaliar a constância e uniformidade na composição de metabólitos secundários, garantindo a padronização do material vegetal no preparado fitoterápico em escala industrial. Permite, ainda, auxiliar no reconhecimento e na compreensão dessas variações, ampliando os conhecimentos sobre interações ecológicas do vegetal com seu ambiente (GOBBO-NETO e LOPES, 2007).

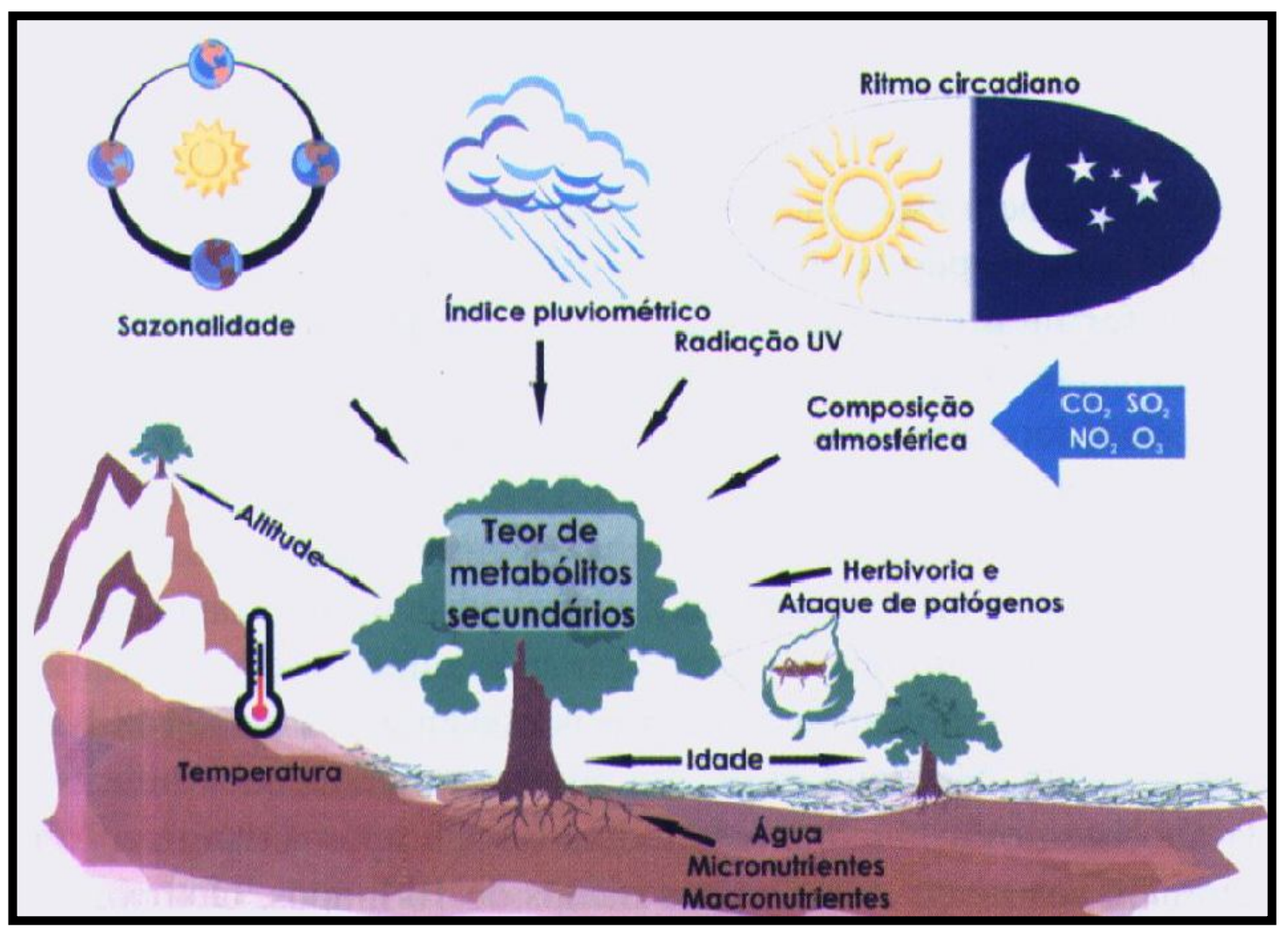

Figura 2: Fatores de influência no acúmulo de metabólitos secundários em plantas (GOBBO-NETO e LOPES, 2007). 


\subsection{MetaboliSMo SECUNDÁRIO}

As milhares de reações químicas catalisadas por enzimas que ocorrem no interior das células são organizadas em seqüências consecutivas, denominadas rotas ou vias metabólicas. Algumas vias degradam nutrientes orgânicos para extrair energia química, convertendo-os em nutriente para as células. A hidrólise destes compostos é acompanhada de grande queda na energia livre, que é liberada. Estas reações químicas são denominadas catabolismo. Outras vias se iniciam com moléculas precursoras pequenas e vão, progressivamente, se transformando em moléculas mais complexas. Tais vias, que requerem energia para o seu funcionamento, são coletivamente denominadas anabolismo. A relação entre as diversas vias catalisadas por enzimas constitui o metabolismo celular (LEHNINGER, 2005).

Os seres vivos são formados por uma complexa diversidade de compostos químicos. Alguns destes, essenciais à vida das células, são denominados metabólitos primários (glicose, colesterol, clorofila, dentre outros); enquanto outros que não lhes são essenciais, são denominados metabólitos secundários (morfina e cânfora, por exemplo) (DEWICK, 2006). Os metabólitos secundários diferem de espécie para espécie qualitativa e quantitativamente, sendo produzidos geralmente em pequenas quantidades. Por conta disso, tais compostos podem ser utilizados em estudos de quimiossistemática (TAIZ e ZEIGER, 2004).

A justificativa para a existência dos metabólitos secundários era motivo de especulação. Alguns exercem papel importante na sobrevivência dos organismos, constituindo substâncias de defesa contra predadores, proteção contra raios UV, agente colorífico para atração de polinizadores, enquanto outros são essenciais na comunicação intra e inter-específica (DEWICK, 2006; LOBO e LOURENÇO, 2007). Como todos derivam de alguns poucos intermediários do metabolismo primário, Bu'Lock defendia a hipótese de que os metabólitos secundários serviriam para escoar o excesso de intermediários chave do metabolismo primário (LOBO e LOURENÇO, 2007). Entretanto, somente no final do século XX compreendeu-se que os metabólitos secundários são resultados da especialização celular e que a expressão diferencial dos genes regula sua

\section{DeniseTaffarello}


síntese durante determinados estágios do desenvolvimento do organismo (GOTTLIEB et al., 1996).

\subsubsection{Origem}

Os metabólitos secundários são originários do processo de conversão de energia luminosa em energia química, a fotossíntese. Alguns metabólitos primários são precursores dos metabólitos secundários. Estes são divididos em três grandes grupos: terpenos (sintetizados a partir do ácido mevalônico, no citoplasma, ou do piruvato e do 3fosfoglicerato, no cloroplasto), compostos fenólicos (obtidos a partir do ácido chiquímico e do ácido malônico) e alcalóides (derivados dos aminoácidos aromáticos triptofano e tirosina, e dos aminoácidos alifáticos ornitina e lisina) (CASTRO et al., 2005).

Na espécie Arrabidaea chica (Humb. \& Bonpl.) Verlot, as substâncias que se constituem no foco deste trabalho são as antocianinas, pertencente à classe dos flavonóides que, por sua vez, pertencem ao grande grupo dos compostos fenólicos.

\subsubsection{Biossíntese dos Compostos Fenólicos}

Os compostos fenólicos são biossintetizados por diferentes rotas, razão pela qual constituem um grupo metabólico bastante heterogêneo (TAIZ e ZIGER, 2004). Estes compostos são sintetizados pela via do ácido chiquímico, a partir de carboidratos, ou pela via do ácido malônico, que se inicia com acetil-coenzima A e malonil-coenzima-A (SIMÕES et al., 2007).

O ácido chiquímico é formado pela condensação do fosfoenolpiruvato com a eritrose-4fosfato. Em seguida, é formado o ácido corísmico através da junção do ácido chiquímico com uma molécula de fosfoenolpiruvato. O ácido corísmico, por sua vez, forma os aminoácidos aromáticos (triptofano, feninalanina e tirosina). Um dos primeiros grupos de compostos fenólicos a ser formado são os fenilpropanóides, os quais são precursores das antocianinas (DEWICK, 2006), pigmentos hidrossolúveis localizados no vacúlo das células vegetais.

\section{DeniseTaffardlo}


A principal enzima da via do ácido chiquímico é a fenilalanina amônia liase (PAL), responsável pela eliminação de uma molécula de amônia da fenilalanina para formar o ácido cinâmico. A PAL está situada em um ponto de ramificação entre os metabolismos primário e secundário, de forma que a reação que ela catalisa é uma etapa reguladora importante na formação de muitos compostos fenólicos (TAIZ e ZEIGER, 2004).

A atividade da PAL é aumentada por fatores ambientais, tais como baixos níveis de nutrientes, luz (efeito no fitocromo) e infecção por fungos. O ponto de controle parece estar no início da transcrição. Por exemplo, a invasão por fungos desencadeia a transcrição do RNA mensageiro que codifica a PAL, aumentando a quantidade de PAL na planta o que, então, estimula a síntese de compostos fenólicos (TAIZ e ZEIGER, 2004).

As antocianinas, pertencentes à família dos flavonóides biossintetizados a partir da via dos fenilpropanóides, constituem uma importante classe de polifenóis (SAVIRANTA et al., 2008). São compostos de biossíntese mista, envolvendo blocos provenientes da via do poliacetato e da via do chiquimato (LOBO e LOURENÇO, 2007). As antocianidinas podem ser mais estáveis na forma de heterosídeos, chamadas antocianosídeos. Os açúcares mais freqüentemente encontrados são: glicose, galactose, ramnose, arabinose e xilose. Os antocianosídeos, após perda de açúcar por hidrólise ácida, são chamados antocianidina ou aglicona. A biossíntese das antocianinas representa um dos estágios finais de oxidação no mecanismo de diferenciação dos flavonóides (Fig. 03) (LOBO e LOURENÇO, 2007; SIMÕES et al., 2007).

As antocianidinas mais freqüentes na natureza são pelargonidina (1), cianidina (2), peonidina (3), petunidina (4) e malvidina (5) (Fig. 4). Os açúcares mais encontrados nas antocianinas são glicose, ramnose, galactose e arabinose (MAZZA e MINIATI, 1993). Estes açúcares ocorrem como monoglicosídeos e triglicosídeos substituídos diretamente na glicona nas posições 3, 5 e 7 (HARBORNE e WILLIANS, 2001).

\section{DeniseTaffarello}




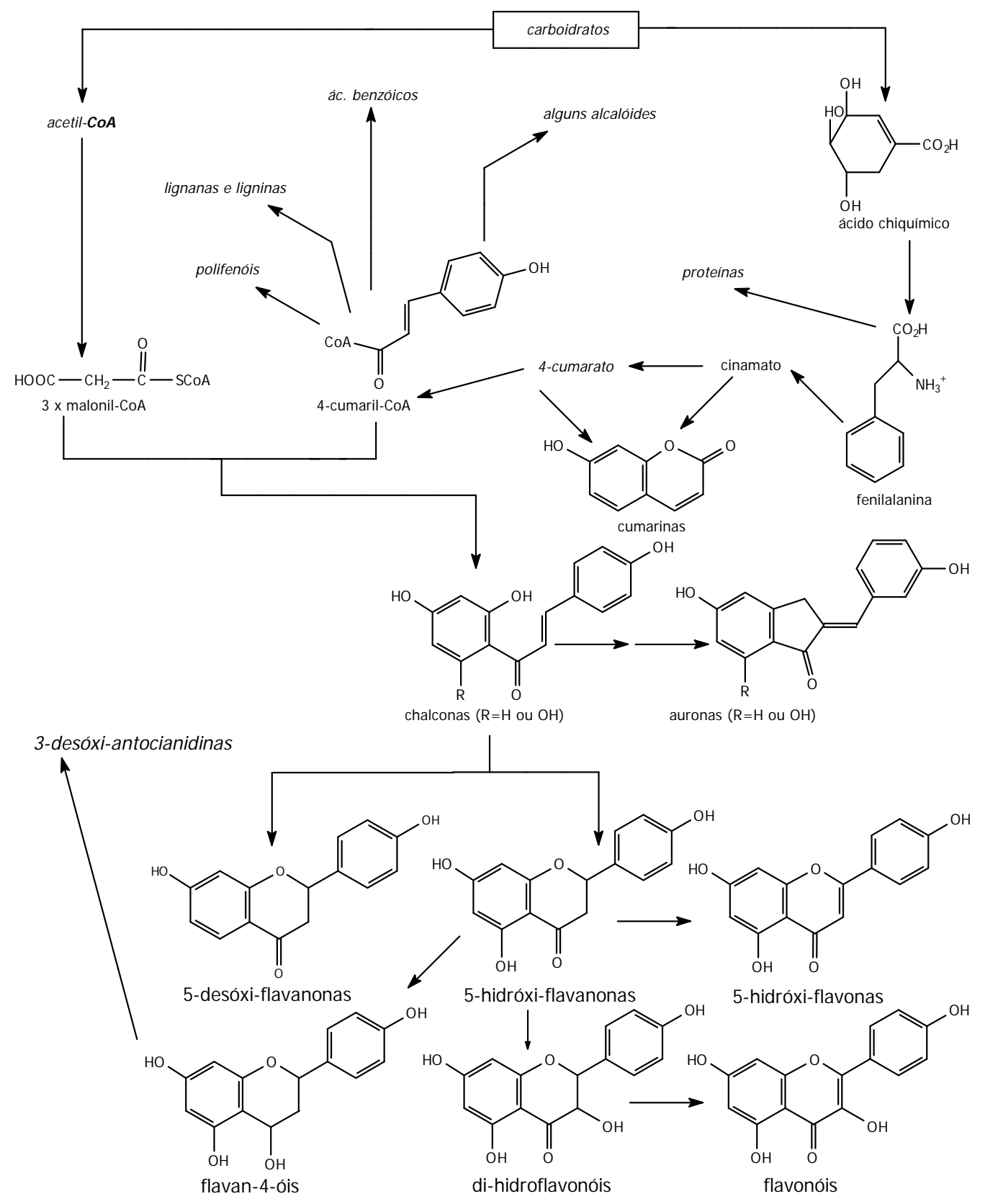<smiles>CO[C@H]1Oc2cc(O)cc(O)c2C(O)C1Oc1c(O)cc(O)cc1C1Oc2c(O)cc(O)cc2[O+]=C1c1ccc(O)cc1</smiles>

Figura 3: Representação esquemática simplificada da biossíntese dos flavonóides. 
<smiles>[R]c1cc([R])c2cc([R])c(-c3cc([R1])c([R19])c([R])c3)[o+]c2c1</smiles>

1<smiles>COc1cc(-c2[o+]c3cc(O)cc(O)c3cc2O)ccc1O</smiles>

$3 \mathrm{R}=\mathrm{H}$

$4_{\mathrm{R}=\mathrm{Me}}$<smiles></smiles>

2<smiles>CCOc1cc(-c2[o+]c3cc(O)cc(O)c3cc2O)cc(O)c1O</smiles>

$$
\begin{aligned}
& 5_{\mathrm{R}=\mathrm{Me}, \mathrm{R}_{1}=\mathrm{H}} \\
& 6 \mathrm{R}=\mathrm{R}_{1}=\mathrm{Me} \\
& 7 \mathrm{R}=\mathrm{H}, \mathrm{R}_{1}=\mathrm{Me}
\end{aligned}
$$

Figura 4: Antocianinas mais conhecidas.

\subsection{Corantes Naturais}

\subsubsection{Pigmentos Vegetais: aplicações industriais}

A pigmentação vegetal é gerada pela estrutura eletrônica do pigmento interagindo com a energia luminosa que altera os comprimentos de onda que são transmitidos e/ou refletidos pelo tecido vegetal. A coloração específica percebida dependerá da capacidade visual do observador. Pesquisas envolvendo a pigmentação, um dos temas mais antigos na botânica, têm trazido diversas descobertas com impacto econômico maior do que somente na área de pigmentos vegetais (DAVIES, 2004). Os pigmentos dos vegetais são de dois tipos principais: os carotenóides, compostos terpênicos de cores amarela, laranja e vermelha, e os flavonóides, compostos fenólicos que incluem grande número de substâncias coloridas, mais comumente representados pelo grupo das antocianinas (TAIZ e ZEIGER, 2004). 
Extratos de plantas têm sido utilizados há séculos para melhorar a aparência ou mesmo para falsificação de alimentos e bebidas, especialmente vinhos (OLIVEIRA, 2001). O uso mais comum tem sido a aplicação de pigmentos como a hena em tatuagens, além de cartamina e indigo para gerar cores brilhantes na confecção de roupas. Foi identificada a utilização de antraquinona, pigmentos indigóides e flavonóides na área têxtil, no quarto século a.C. pelos egípcios (ORSKA-GAWRYS et al., 2003). A utilização de extrato de cartamina para colorir o embrulho das múmias foi relatada, além de evidências escritas, datadas de 4600 anos atrás, documentando a utilização por humanos do indigo. Séculos mais tarde, de 1501 até cerca de 1850, destacou-se a intensa exploração econômica do paubrasil (Caesalpinia echinata Lam.), cuja madeira fornecia corante vermelho, denominado brasileína, cobiçado pela indústria têxtil da Europa, para tingir penas e algodão (REZENDE et al., 2004; HELLMANN, 2006). O encerramento deste ciclo econômico deixou suas matas totalmente exauridas, sendo que em 1920 o pau-brasil foi considerado extinto. Posteriormente, em 1961, o presidente Jânio Quadros aprovou o projeto de lei que declarava o pau-brasil "árvore símbolo nacional."

Apesar do papel vital das clorofilas e dos pigmentos carotenóides na fotossíntese, o impacto econômico dos pigmentos não fotossintéticos é, freqüentemente, maior. Isso se deve à sua importância em fornecer sabor, aroma e coloração em chás, vinhos e outras bebidas, além de sua utilização como corantes naturais pela indústria alimentícia, farmacêutica e cosmética. A clorofila tem seu emprego limitado na indústria alimentícia devido à sua baixa estabilidade durante o processamento do alimento ou em resposta às condições de $\mathrm{pH}$ ou de luminosidade no produto final (DAVIES, 2004).

A partir do desenvolvimento de métodos de síntese para corantes, em meados do século XIX, especialmente na Inglaterra e na Alemanha, produtos altamente tóxicos foram sendo substituídos por corantes sintéticos, sem restrições imediatas. Com o avanço das técnicas analíticas, dos estudos toxicológicos e das pesquisas farmacológicas, foram constatadas as propriedades tóxicas dos corantes sintéticos, sendo que alguns destes foram proibidos (OLIVEIRA, 2001).

Estudos realizados no início do século XXI (OLIVEIRA, 2001; MOREIRA, 2003) relataram um retorno à utilização de corantes naturais e aumento de interesse em novas fontes naturais, melhorando seu desempenho nas aplicações pelas indústrias alimentícia, 
farmacêutica e cosmética. Além dos possíveis problemas toxicológicos relacionados aos corantes sintéticos, há, atualmente, uma grande demanda por produtos considerados naturais por parte dos consumidores.

Há quatro tipos de pigmentos vegetais amplamente utilizados como corantes pela indústria: urucum, betalaínas, curcumina e antocianinas (Fig. 5). Juntos com a cochinilha ${ }^{4}$, são responsáveis por mais de $90 \%$ do mercado de corantes naturais. Pigmentos utilizados como corante em menor quantidade incluem os carotenóides, xantofila e luteína. Os tipos de pigmentos utilizados nas diferentes aplicações industriais são determinados por sua solubilidade e, para os pigmentos solúveis em água, pelo seu comportamento em resposta ao $\mathrm{pH}$. As antocianinas e betalaínas são solúveis em água, enquanto que as clorofilas, a curcumina e os carotenóides são solúveis em óleo. (DAVIES, 2004).

O urucum é um dos primeiros corantes que foram descritos, cuja aplicação ocorre na indústria de alimentos, têxtil e cosmética. É extraído da resina obtida com a casca das sementes do arbusto tropical Bixa orellana, podendo atingir mais de $10 \%$ do peso seco das sementes. Foi utilizado pelos indígenas da América Tropical como fonte de pigmentos, nos tempos pré-Colombianos. O pigmento principal do urucum é o apocarotenóide cis-bixina, que fornece coloração amarelo-alaranjado. Beterraba é a principal fonte de betalaínas utilizadas como corantes, principalmente do pigmento vermelho betanina. Curcumina é o pigmento majoritário do condimento turmérico, extraído dos rizomas de Curcuma longa (Zingiberaceae), espécie asiática (cúrcuma) que fornece corante amarelo aos alimentos (DAVIES, 2004).

As antocianinas foram inicialmente descritas como indicadores de $\mathrm{pH}$ e são amplamente utilizadas para fornecer cores do avermelhado ao azul em alimentos. Embora presentes em diversas fontes, extratos comerciais de antocianas são predominantemente obtidos de uva (Vitis spp.) pela indústria vinícola (DAVIES, 2004).

\footnotetext{
${ }^{4}$ Pigmento derivado de um inseto, Dactylopius coccus Costa, 1829 (Hemiptera, Geometroidea).
}

\section{DeniseTaffarello}




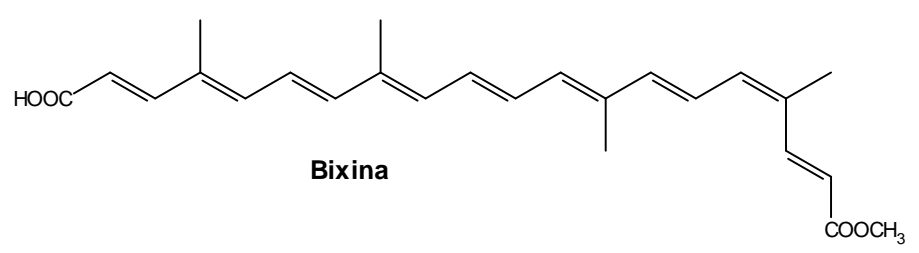<smiles>COc1cc(/C=C/C(=O)CC(=O)/C=C/c2ccc(O)c(O)c2)ccc1O</smiles><smiles>COc1cc(OC)c2cc(O)cc(OC)c2c1</smiles>

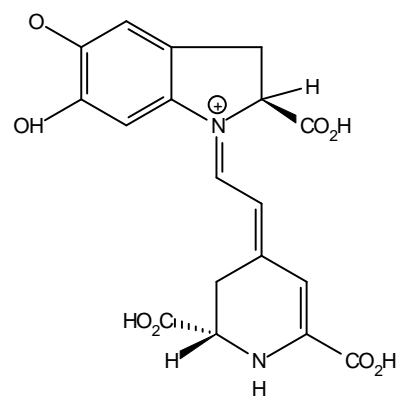

Betanina

Figura 5: Representação diagramática dos principais pigmentos vegetais amplamente utilizados como corantes pela indústria (DAVIES, 2004).

Até início dos anos 2000, vinte antocianinas diferentes foram descritas em uvas, entretanto, as preparações comerciais continham apenas os relativamente simples 3diglicosídeo de cianidina e 3,5-diglicosídeo de cianidina, delfinidina e malvidina. Estes apresentam estabilidade de coloração limitada pelo pH (MELO et al., 2007), conseqüentemente, restringindo sua aplicação industrial. Este fato estimulou a pesquisa de fontes mais complexas e, conseqüentemente, mais estáveis de antocianinas para aumentar suas aplicações industriais. Atualmente, são disponíveis extratos comerciais de Ribes nigrum (uva-passa), Sambucus nigra (sabugueiro) e Brassica oleracea (repolho-roxo). Outrossim, os extratos de Raphanus sativus (rabanete) e Solanum tuberosum (batata, variedades de casca vermelha) são fontes potenciais de antocianinas aciladas para substituir o corante sintético Allura Red (DAVIES, 2004).

O interesse em novas fontes de antocianinas tem se intensificado devido à recente evidência dos benefícios à saúde promovidos por estas (ZAFRA-STONE et al., 2007), através de diversos mecanismos de ação, incluindo a capacidade antioxidante (MOYER et 
al., 2002; SRIVASTAVA et al., 2007). Segundo Oliveira (2001), não havia relatos de efeitos tóxicos causados pela ingestão de antocianinas, porém um estudo de revisão da literatura posterior indicou a necessidade de avaliações que garantam a segurança dos extratos de plantas ricos em antocianinas (PASCUAL-TERESA e SANCHESBALLESTA, 2008).

As antocianinas desempenham importante papel nas interações de plantas com insetos para atração de polinizadores e dispersão de sementes. Também têm apresentado um papel importante nas interações alelopáticas ligadas à defesa contra herbívoros. Esta classe de compostos demonstrou atividades antioxidante, anti-inflamatória, antiaterosclerótica e propriedades anticâncer em diversos estudos (KONG et al., 2003; ZAFRA-STONE et al., 2007; SRIVASTAVA et al., 2007).

Atualmente, corantes naturais utilizados pela indústria são, em sua maioria, obtidos diretamente do material vegetal extraído por métodos tradicionais. Entretanto, o rendimento e a qualidade (composição química) dos pigmentos são afetados por fatores sazonais, ambientais e de variação genotípica da espécie. Portanto, há grande interesse em aplicar ferramentas biotecnológicas para a obtenção de corantes naturais a partir de extratos vegetais, garantindo uniformidade, altos rendimentos e segurança do produto (OVANDO-CHACÓN e WALISZEWSKI, 2005).

Tendo em vista que os potenciais riscos da liberação de organismos geneticamente modificados na biosfera continuam sendo monitorados, sem dados conclusivos até o momento (JULSING et al., 2007), buscou-se, neste estudo, abordar o atual problema encontrado pela indústria extrativa sem a utilização da tecnologia do DNA recombinante, e sim, através de tratamento enzimático. Outra justificativa foi a escolha de metodologia extrativa simples, vantajosa no aspecto de apresentar menores custos, em relação às técnicas mais avançadas de biotecnologia. Segundo Julsing et al. (2007), a utilização de plantas geneticamente modificadas como fonte para a obtenção de extratos com aplicações industriais não tem sido aceita pelos consumidores, devido à progressiva popularidade da fitoterapia e à idéia equivocada de que os produtos obtidos da natureza são seguros.

\section{DeniseTaffarello}




\subsection{ESPÉCIE ESTUdAda: ARRAbidaEa CHICA (HUMb. \& BonPl.) Verlot (BIGNONIACEAE)}

\subsubsection{Relações filogenéticas na família Bignoniaceae}

A família Bignoniaceae compreende 78 gêneros e 832 espécies (LOHMANN e ULlOA, 2008). Na América tropical, há aproximadamente 600 espécies, sendo que Tabebuia, Jacaranda, Arrabidaea, Anemopaegma e Adenocalymma são os maiores gêneros e juntos englobam quase metade das espécies pertencentes à família (LOHMANN, 2004).

Bignoniaceae é considerado um grupo monofilético, excluindo o gênero Paulownia e a tribo Schlegelieae que atualmente fazem parte das famílias "Paulowniaceae" e "Schlegeliaceae" (FISCHER et al. 2004; SPANGLER e OLMSTEAD 1999). Dentro da ordem Lamiales, esta família está filogeneticamente próxima de Avicenniaceae, Lamiaceae, Lentibulariaceae, Phrymaceae, Schlegeliaceae, Verbenaceae e Acanthaceae (BREMER et al., 2001). A família Bignoniaceae está dividida em sete tribos, que diferem entre si principalmente quanto a distribuição geográfica, hábito e morfologia do fruto: Tecomeae, Oroxyleae, Bignonieae, Eccremocarpeae, Tourretieae, Coleeae e Crescentieae (LOHMANN, 2004). As tribos Crescentieae, Coleeae e Bignonieae, a qual inclui o gênero Arrabidaea, são consideradas monofiléticas (SPANGLER e OLMSTEAD 1999).

A tribo Bignonieae constitui um clado de lianas neotropicais grande e morfologicamente diverso. O grupo está amplamente distribuído nos neotrópicos, ocorrendo na América Central, Amazônia, floresta Atlântica do sudeste do Brasil, e nas florestas secas abertas e savanas da Argentina, Bolívia, Brasil e Paraguai. A tribo se distingüe pela anatomia da madeira e por folhas compostas, opostas, que freqüentemente apresentam o folíolo terminal substituído por uma gavinha (LOHMANN, 2006). Apesar da diversidade morfológica e importância ecológica desta tribo, o grupo é sistematicamente problemático e sua classificação em nível de gênero permanecia incerta, devido principalmente a padrões conflitantes de variação morfológica no grupo (GENTRY, 1973). Análises filogenéticas baseadas em seqüências de DNA dos cloroplastos $(n d h F)$ e nuclear $(P e p C)$ indicaram que o gênero Arrabidaea não constitui um grupo monofilético (Fig. 6).

\section{DeniseTaffardlo}


Neste caso, taxa previamente colocados dentro do gênero se enquadram em outros grupos (clados Cuspidaria, Xylophragma e Bromelíade), cada um dos quais também inclui representantes de outros gêneros tradicionalmente reconhecidos (LOHMANN, 2006).

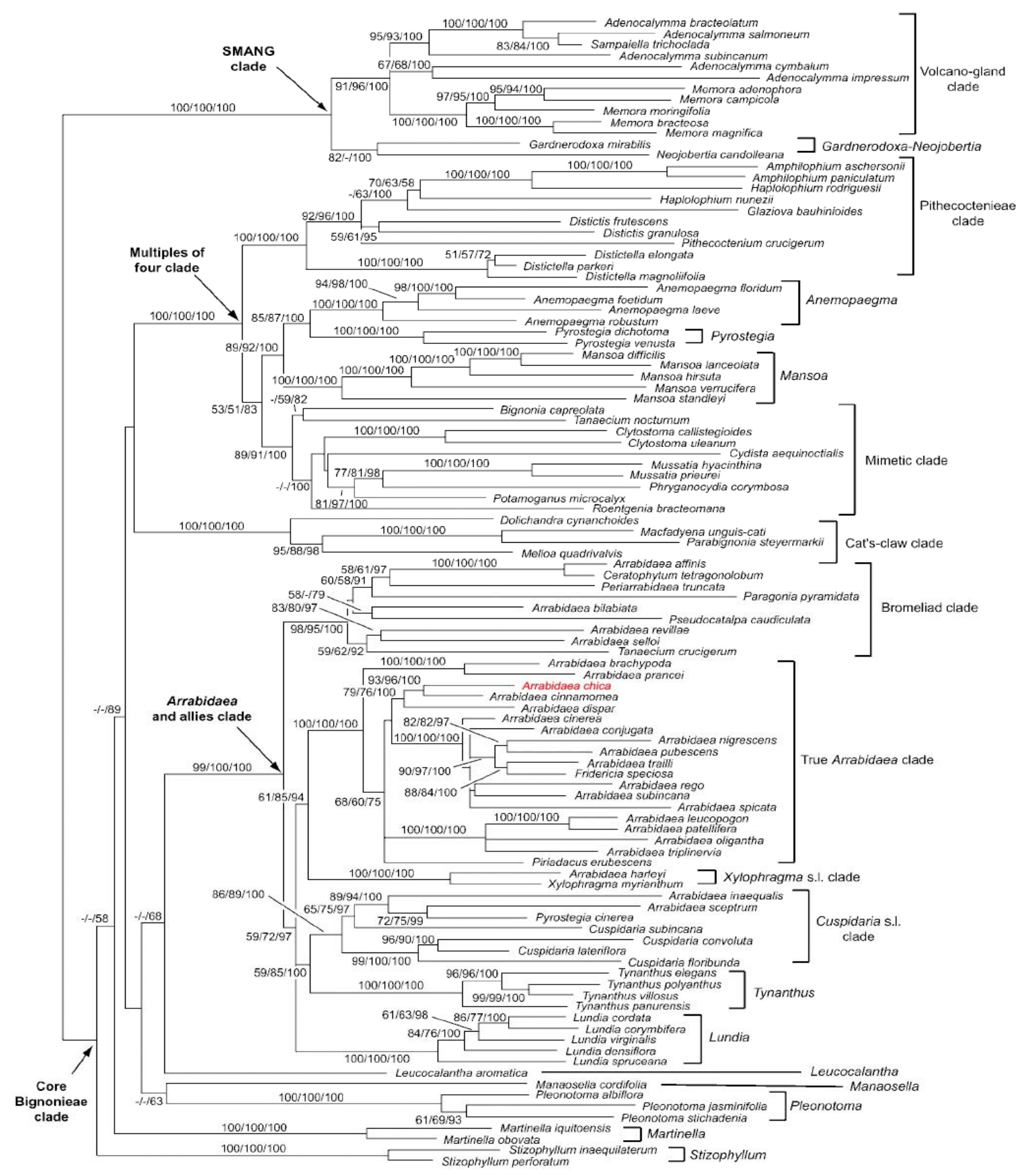

Figura 6: Árvore filogenética baseada nas sequiências de $n d h F$ e $P e p C$ combinadas, para 104 espécies de Bignonieae (modificado de LOHMANN, 2006).

\section{DeniseTaffarello}




\subsubsection{Aspectos botânicos}

A espécie Arrabidaea chica (Humb. \& Bonpl.) Verlot (Fig. 7) é uma liana lenhosa, com tronco quadrangular, acinzentado, e ramos cinza-claros, estriados. As folhas são compostas bi ou trifolioladas, de folíolos glabros, oblongo-lanceolados e com glândulas esparsas. Apresenta flores campanuladas de cor rósea ou violácea, dispostas em panículas terminais (Fig. 8) (LOHMANN e HOPKINS, 1999; LORENZI e MATOS, 2002). A espécie é conhecida popularmente como "pariri” (no Pará), "crajiru" (no Amazonas), "puca-panga", "coapiranga", "chica” ou "cipó-cruz", é nativa de quase todo o Brasil e muito comum na Floresta Amazônica (VON POSER et al., 2000), um dos mais complexos ecossistemas da Terra em equilíbrio, onde participam fatores como umidade, alta precipitação e reciclagem da matéria orgânica. Todavia, o desmatamento vem quebrando este equilíbrio de modo acelerado, com risco do desaparecimento de riquíssimo número de espécies da flora ainda não convenientemente estudadas (KALIL FILHO et al., 2000).

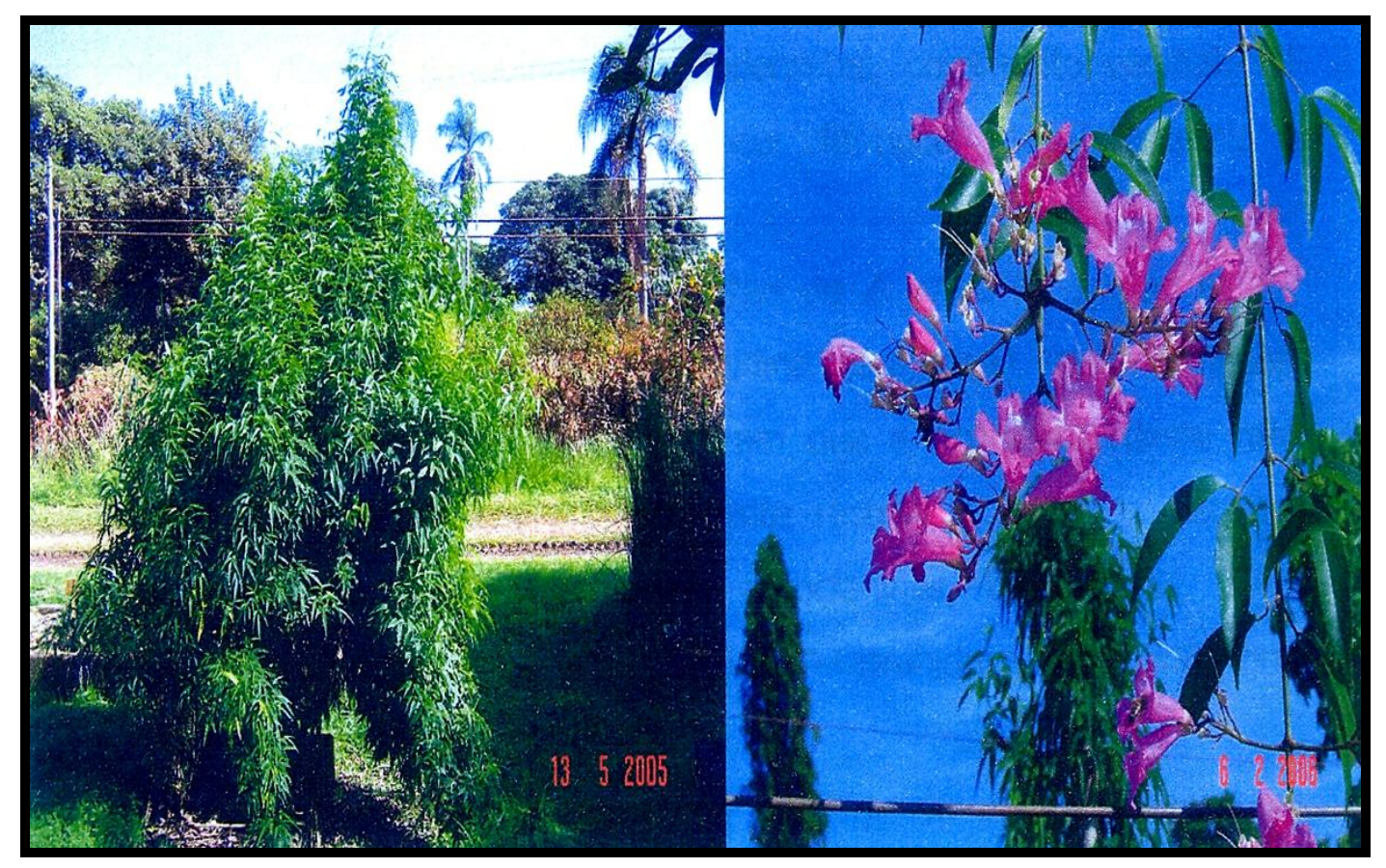

Figura 7: Exemplar de A.chica cultivada no campo experimental do CPQBA. 


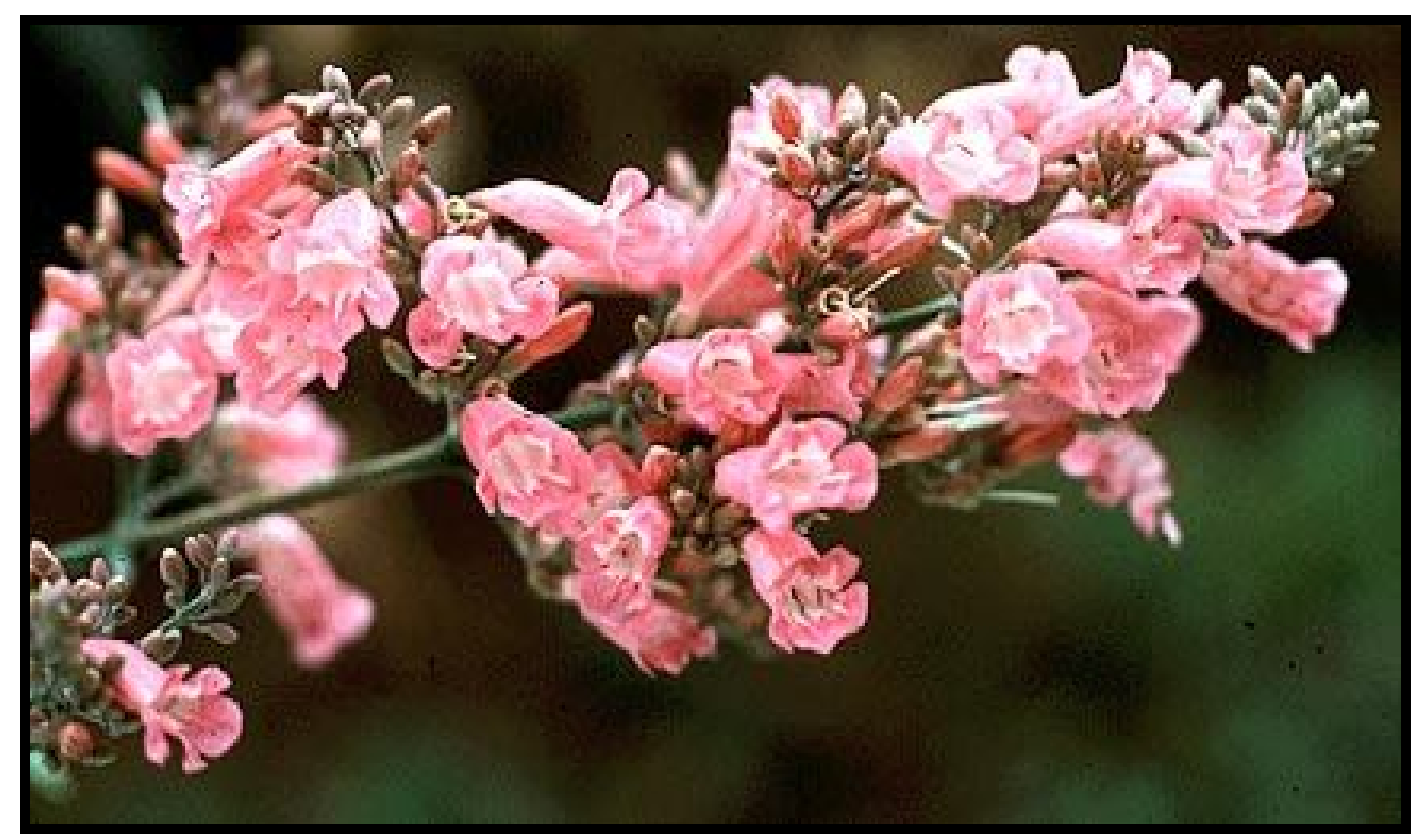

Figura 08: Flores de A. chica dispostas em panículas terminais. Fotografia de A. Gentry, do acervo de plantas tropicais do Missouri Botanical Garden.

\subsubsection{Propriedades terapêuticas e uso popular}

Na região Nordeste do Brasil, folhas de A. chica são utilizadas em tatuagens pelos índios devido aos pigmentos carajurina e carajurona (CORRÊA, 1926; CHAPMAN et al., 1927; ZORN et al., 2001). No Estado do Maranhão, extratos hidroetanólicos de folhas de A. chica foram utilizados no tratamento de cálculos renais e da hipertensão arterial sistêmica (PESSOA et al., 2006). A medicina tradicional atribui à espécie um amplo espectro de propriedades, tais como antiinflamatórias, adstringentes e terapêuticas, além de seu emprego no tratamento de enfermidades da pele (psoríase, empinagem, feridas, úlceras, piodermites) cólicas intestinais, diarréia sanguinolenta, leucorréia, corrimento vaginal, sífilis, conjuntivite, anemia, leucemia, câncer de boca e de útero, além de ser utilizada para a prevenção de cáries e como cosmético (GENTRY, 1992; KALIL FILHO, 2000). Devido ao seu uso tradicional, recentemente extratos de folhas de A. chica começaram a ser utilizados em formulações de xampus e sabonetes, por pequenas indústrias cosméticas da região norte do Brasil (SCHIOZER et al., 2006).

Duke e Vasquez (1994) relataram que folhas frescas de A. chica são empregadas em decocção sozinhas ou com os frutos de Renealmia alpinia na pigmentação de fibras de Astrocaryum chambyra para fazer tatuagens. Este pigmento também é utilizado para tratar 
infecções da pele e herpes. Os índios "Chami" utilizam o pigmento vermelho para tingir cestas. Os "Tikuna" usam infusões das folhas contra conjuntivites. "Jivaros" mastigam as folhas com argila para escurecer os dentes. Os residentes do "Tapajó" usam o chá das folhas para anemias, desordens sangüíneas e inflamação. Kalil Filho et al. (2000) descreveram que folhas de A. chica submetidas à fermentação e manipuladas como a anileira (Indigofera spp.) fornecem corante vermelho-escuro ou vermelho-tijolo utilizado pelos índios para pintura do corpo e utensílios. Algumas tribos preparam uma infusão das folhas, utilizada no tratamento de conjuntivite aguda. Contra ataque de insetos, utilizam uma pasta na forma de cataplasma. O preparo de tinturas a partir de folhas de A. chica é feito através da adição de 100 g de folhas secas em álcool 92 graus GL. A utilização dessa tintura é indicada para o tratamento de anemias, como cicatrizante suave de espinhas em uso tópico e, sobretudo, no preparo de pomadas e cremes (BORRÁS, 2003). Espécies pertencentes ao gênero Arrabidaea são utilizadas na medicina tradicional para assepsia de feridas e no tratamento de desordens intestinais (CORRÊA, 1926).

\subsubsection{Composição química}

O gênero Arrabidaea é fonte de antocianinas, flavonóides e taninos (HARBORNE, 1967; TAKEMURA, 1995; ZORN et al., 2001; DEVIA et al., 2002; ALCERITO, 2002; PAULETTI et al., 2003). Pauletti, et al. (2003) descobriram novas glicosilxantonas isoladas do caule de A. samydoides que apresentaram propriedades antioxidantes. Alcerito et al. (2002) isolaram quatro flavonóides com atividade antifúngica das folhas de $A$. brachypoda.

O primeiro estudo fitoquímico das folhas de A. chica (CHAPMAN et al., 1927) relata o isolamento de 3-desoxiantocianidina (carajurina). Posteriormente, foi proposto que a ocorrência deste raro pigmento em Bignoniaceae era provavelmente restrita à Arrabidaea chica (SCOGIN, 1980; HARBORNE, 1998). Estudos posteriores resultaram no isolamento de antocianinas, fito-esteróis, 7,4'-di-hidroxi-5-metaxoxiflavona e 6,3',4'-tetrahidroxi-5metoxiflavona (carajuruflavona) (TAKEMURA et al., 1995).

Williams e Grayer (2004) relataram que mais de 50 novas antocianinas foram isoladas a partir de plantas, não somente das pétalas das flores, mas também de frutos,

\section{DeniseTaffarello}


folhas e sementes Dentre as novas agliconas destacam-se as 3-desoxiantocianidinas (Fig. 9), a carajurona (8), 6,7-dihidroxi-5,4'-dimetoxiflavilium (carajurina) (9), a 6,7,3'trihidroxi-5-dimetoxi-flavilium (10) e a 6,7,3',4'-tetrahidoxi-5-metoxi-flavilium (11), que foram isoladas das partes aéreas de $A$. chica.<smiles></smiles><smiles>COc1c(O)c(O)cc2[o+]c(-c3ccc(O)c(O)c3)ccc12</smiles><smiles>COc1ccc(-c2ccc3c(OC)c(O)c(O)cc3[o+]2)cc1</smiles><smiles>COc1ccc(-c2ccc3c(OC)c(O)c(O)cc3[o+]2)cc1O</smiles>

Figura 9: Agliconas isoladas das folhas de A. chica.

A molécula de antocianina contém o íon flavílio ou 2-fenilbenzopirílio (12), e um açúcar, podendo conter ainda um ácido alifático ou aromático. A antocianina, após perda de açúcar por hidrólise ácida, é chamada antocianidina ou aglicona. As antocianinas são raramente isoladas e identificadas devido à sua grande instabilidade (OLIVEIRA, 2001).

\subsubsection{Extratos de $A$. chica tratados com xilanases}

Kim et al. (2005) estudaram o enriquecimento da extração de pigmentos vermelhos pela incubação prévia do material vegetal na presença de xilanase oriunda de Bacillus sp. Os pigmentos extraídos das raízes de plantas da família Boraginaceae apresentaram diversas atividades biológicas, tais como antiinflamatória, bactericida, fungicida, 
imunoestimiladora, anticâncer, analgésica e antipirética, além de seu emprego como corante. $\mathrm{O}$ rendimento dos processos de obtenção dos pigmentos foi influenciado pelas condições de extração e pelos solventes utilizados. A incubação prévia com xilanase de Bacillus sp. aumentou o rendimento de extração dos pigmentos em $80 \%$ por facilitar o desprendimento dos corantes das matrizes vegetais. Também foi reduzido o tempo de extração: 15 minutos de extração com atuação de xilanase, comparado com 10 horas de extração normal, sem ação enzimática, para obtenção da mesma quantidade de pigmentos.

Com bases nos estudos realizados por Kim et al. (2005), este projeto desenvolveu um novo processo de extração, buscando a produção de extratos padronizados em pigmentos avermelhados, a partir de folhas de A. chica, com potencial aplicação pela indústria cosmética e farmacêutica. Através de uma inovação biotecnológica foi verificado o efeito de enzimas oriundas do Bacillus pumilus sobre o extrato de A. chica, visando o desenvolvimento de nova metodologia para padronização dos extratos, aumentando o rendimento de antocianidinas.

\subsubsection{Estudos preliminares para produção em larga escala do corante extraído de $A$. chica}

O Centro Pluridisciplinar de Pesquisas Químicas, Biológicas e Agrícolas (CPQBA) da Universidade Estadual de Campinas (Unicamp) desenvolveu um projeto de pesquisa (FAPESP 03/09317-5) para a domesticação e produção em larga escala de A. chica, cujo corante vermelho extraído das folhas tem potencial para ser empregado em produtos cosméticos, substituindo os corantes sintéticos atualmente utilizados.

Para o desenvolvimento do trabalho foram introduzidos no campo experimental do CPQBA diferentes acessos da espécie, isto é, exemplares oriundos de localidades diferentes (Tabela 2 e Fig. 10), com o objetivo de selecionar uma variedade que produzisse maior teor de pigmentos em relação à biomassa. 
Atualmente, há um novo projeto (FAPESP 07/52739-9) envolvendo o CPQBAUnicamp, o Laboratório Thomson/IQ - Unicamp e o Instituto Agronômico de Campinas, que deu continuidade a este trabalho.

Tabela 2: Locais originários dos exemplares de $A$. chica cultivados experimentalmente na Coleção de Plantas Medicinais e Aromáticas do CPQBA.

\begin{tabular}{cccc}
\hline Acesso & Local & Latitude & Longitude \\
\hline 01 & CPQBA (SP) & $22^{\circ} 47^{\prime} 46^{\prime \prime} \mathrm{S}$ & $47^{\circ} 07^{\prime} 09^{\prime \prime} \mathrm{W}$ \\
02 & Campo Grande (MS) & $20^{\circ} 26^{\prime} 36^{\prime} \mathrm{S}$ & $54^{\circ} 38^{\prime} 50^{\prime} \mathrm{W}$ \\
03 & Tijucas do Sul (PR) & $25^{\circ} 56^{\prime} 15^{\prime \prime} \mathrm{S}$ & $49^{\circ} 11^{\prime} 15^{\prime} \mathrm{W}$ \\
04 & Manaus (AM) & $03^{\circ} 06^{\prime} 08^{\prime \prime} \mathrm{S}$ & $60^{\circ} 01^{\prime} 25^{\prime} \mathrm{W}$ \\
05 & Curitiba (PR) & $25^{\circ} 25^{\prime} 07^{\prime} \mathrm{S}$ & $49^{\circ} 17^{\prime} 10^{\prime \prime} \mathrm{W}$ \\
06 & Paulínia (SP) & $22^{\circ} 45^{\prime} 42^{\prime \prime} \mathrm{S}$ & $47^{\circ} 09^{\prime} 14^{\prime \prime} \mathrm{W}$ \\
07 & Campinas (SP) & $22^{\circ} 54^{\prime} 22^{\prime \prime} \mathrm{S}$ & $47^{\circ} 03^{\prime} 41^{\prime \prime} \mathrm{W}$ \\
\hline
\end{tabular}

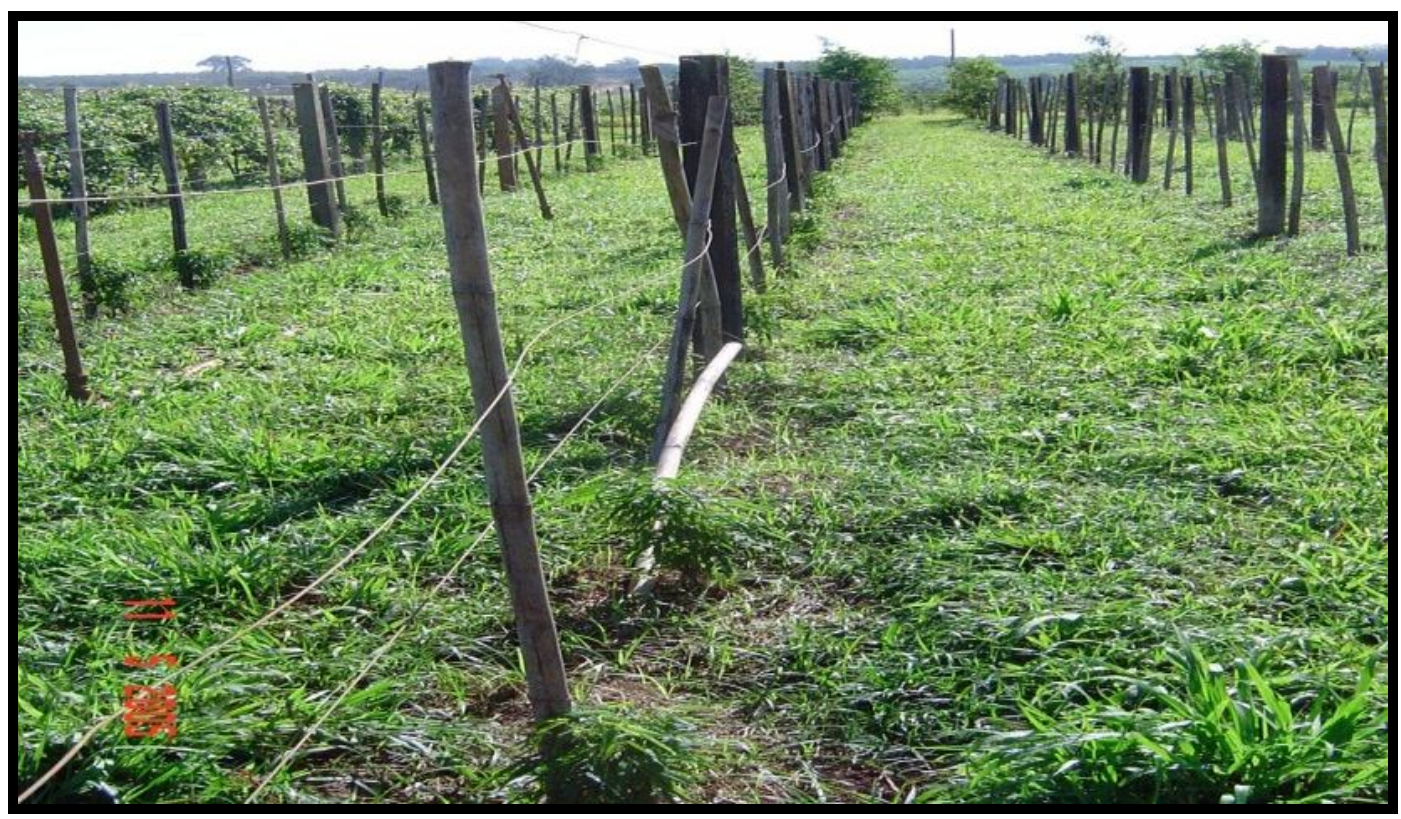

Figura 10: Plantas de acessos diferentes de Arrabidaea chica Verlot cultivadas no banco de germoplasma do CPQBA-Unicamp. 
Condusões 


\section{CONCLUSÕES}

- Folhas de Arrabidaea chica do acesso 06 (Manaus aclimatado às condições de Paulínia) foram selecionados para o desenvolvimento do corante, por possuírem maior teor de pigmentos vermelhos em relação à biomassa.

- O tratamento enzimático com xilanases de Bacillus pumilus foi capaz de liberar as agliconas dos antocianosídeos.

- O tratamento enzimático de $A$. chica permitiu produzir extratos brutos enriquecidos nas agliconas livres: pigmento 1: 6,7,3',4'-tetra-hidroxi-5-metoxiflavílium (m/z 301); pigmento 2: 6,7,4'-trihidroxi-5-metoxi-flavílium (m/z 285); pigmento 3: 6,7-dihidroxi-5,4'-dimetoxi-flavílium, a carajiruna (m/z 299).

- O rendimento de extração com o tratamento enzimático foi seletivo para a extração das agliconas livres, explicando a queda nos rendimentos finais de extração.

- Extratos produzidos com xilanases que apresentaram maior teor de pigmentos em relação à biomassa foram obtidos a partir de folhas coletadas em março e setembro (1,25mg. $\mathrm{g}^{-1}$ e $1,7 \mathrm{mg} \cdot \mathrm{g}^{-1}$, respectivamente), indicando que o ritmo circadiano influencia a produção de antocianinas.

- A antocianina m/z 463 favoreceu a ação cicatrizante do extrato bruto de Arrabidaea chica.

- A atividade cicatrizante do extrato bruto de A. chica é inversamente proporcional ao aumento da aglicona carajiruna (m/z 299), visto que a proliferação de fibroblastos só ocorreu em amostras que não foram submetidas ao tratamento enzimático.

- As atividades anticâncer e antioxidante da espécie estão diretamente relacionadas com o aumento do teor de agliconas livres no extrato bruto de A. chica. 


\subsection{SUGESTÕES PARA TRABALHOS FUTUROS}

- Isolar os pigmentos para validação de metodologias analiticas.

- Realizar estudo sazonal dos acessos de Arrabidaea chica Verlot para padronização da matéria-prima vegetal.

- Realizar a validação dos processos de extração, o que permite assegurar que o sistema funciona adequadamente dentro das condições do experimento.

- Avaliar a diversidade genética dos diferentes acessos de A. chica.

- Avaliar a atuação de amilases, celulases e $\beta$-glicosidases na extração de compostos fenólicos de folhas de A. chica, comparando com a eficiência de xilanases de Bacillus pumilus nos processos de extração. 


\section{RefeûniasBibliogófices}


ALCERITO, T.; BARBO, F. E.; NEGRI, G.; SANTOS, D.Y.A.C.; MEDA, C. I.; YOUNG, M.C.M.; CHÁVEZ, D.; BLATT, C.T.T. Foliar epicuticular wax of Arrabidaea brachypoda: flavonoids and antifungal activity. Biochemical and Systematics Ecology, v. 30, p. 677-683, 2002.

BAILEY, M. J.; BIELY, P.;POUTANEN, K. Interlaboratory testing of methods for assay of xylanase activity. Journal of Biotechnology, v. 23, p.257-270,1992.

BALUNAS, M. J.; KINGHORN, D. A. Drug discovery from medicinal plants. Life Sciences, v. 28, p. 431-441, 2005.

BELIËN, TIM; CAMPENHOUT, S. V.; ROBBEN, J.; VOLCKAERT, G. Microbial Endoxylanases: effective weapons to breach the plant cell-wall barrier ou, rather, triggers of plant defense systems? Molecular Plant-Microbe Interactions, v. 19, n.10, p. 1072-1081, 2006.

BENEVIDES, P. J. C. Estudo fitoquímico guiado por bioensaios em algumas espécies da Mata Atlântica e Floresta Amazônica. 226f. Tese (Doutorado em Ciências) - Instituto de Química, Universidade de São Paulo, São Paulo, 2001.

BORRÁS, M. R. L. Plantas da Amazônia: medicinais ou mágicas - Plantas comercializadas no Mercado Municipal Adolpho Lisboa. Manaus: Ed. Valer, 2003.

BREM, B.; SEGER, C.; PACHER, T.; HARTL, M.; HADACEK, F.; HOFER, O.; VAJRODAYA, S.; GREGER, H. Antioxidant dehydrotocopherols as a new chemical character of Stemona species.Phytochemistry, v. 65, p. 2719-2729, 2004.

BREMER, K.; BACKLUND, A.; SENNBLAD, B.; SWENSON, U.; ANDREASEN, K.; HJERTSON, M.; LUNDBERG, J.; BACKLUND, M.; BREMER, B. A phylogenetic analysis of $100+$ genera and $50+$ families of euasterids based on morphological and molecular data with notes on possible higher level morphological synapomorphies. Plant Systematics and Evolution, v. 229, p. 137-169, 2001.

BUSS, A.D.; WAIGH, R.D. Antiparasitic drugs. In.: WOLFF, M.E. Medicinal Chemistry and Drug Discovery. New York: Wiley-Interscience, 1995. p.1021-1028.

CAI, Y.-Z.; SUN, M.; XING, J.; LUO, Q.; CORKE, H. Structure-radical scavenging activity relationships of phenolic compounds from traditional Chinese medicinal plants. Life Sciences, v. 78, p. 2872-2888, 2006.

CALIXTO, J. B. Desenvolvimento de medicamentos: Ensaios Pré-Clínicos. Médicos, v. 6, p. 22-25, 1998.

CASTRO, P. R.; KLUGE, R. A.; PERES, L.E.P. Manual de fisiologia vegetal: teoria e prática. Piracicaba: Agronômica Ceres, 2005.

\footnotetext{
${ }^{*}$ De acordo com:

ASSOCIAÇÃO BRASILEIRA DE NORMAS TÉCNICAS. NBR 6023: Informação e documentação: referências: elaboração. Rio de Janeiro, 2002.
} 
CHAPMAN, E.; PERKIN, A.G.; ROBINSON, R. The colouring matters of carajura. Journal of the Chemical Society, v. 2, p. 3015-3041, 1927.

CORREAA, P.M. Dicionário das plantas úteis do Brasil e das exóticas cultivadas. Rio de Janeiro: Imprensa Nacional, 1926. p. 31-39.

CRAGG, G. M.; NEWMAN, D. J. Discovery and development of antineoplasic agents from natural sources. Cancer Investigation, v.17, n. 2, p.153-163, 1999.

CRAGG, M.G.; NEWMAN, D. J. Plants as source of anticancer agents. Journal of Ethnopharmacology, v. 100, p. 72-79, 2005.

DAVIES, K. Plant pigments and their manipulation: Annual Plant Reviews. New York: Academic Press Blackwell, 2004. v.14.

DECRETO $\mathrm{N}^{\circ}$ 6041, de 08 de fevereiro de 2007. Diário Oficial da União. Disponível em: <http://www.planalto.gov.br/ccivil_03/_Ato2007-2010/2007>. Acesso em: 15 jul. 2007.

DELITTI, W. B. C. Manifesto de apoio do Instituto de Biociências (USP) ao INPE, 07/02/2008. Disponível em: 〈www.ib.usp.br>. Acesso em: 12 fev. 2008.

DEVIA, B.; LLABRES, G.; WOUTERS, J.; DUPONT, L.; ESCRIBAN-BAILON, M. T.; PASCUAL-TERESA, S.; AMGENOT, L.; TITS, M. New 3-deoxyanthocyanidins from leaves of Arrabidaea chica. Phytochemical Analysis, v. 13, p. 114-120, 2002.

DEWICK, P. M. Medicinal Natural Products: A Biosynthetic Approach. United King: John Wiley \& Sons, 2006.

DUARTE, M. C. T.; PORTUGAL, E. P.; PONEZI, A. N.; FRANCO T. T. Alkalophilic xylanases production from bacteria. BRAZILIAN SYMPOSIUM ON THE CHEMISTRY OF LIGNINS AND OTHER WOOD COMPONENTS， $5^{\text {th }} ， 1997$, Curitiba. Proceedings... Curitiba: UFPR, 1997. p. 340-345.

DUARTE, M. C. T.; PORTUGAL, E. P.; PONEZI, A. N.; FRANCO, T. T. Otimização da produção de xilanases alcalinas por diferentes cepas de Bacillus pumilus. SIMPÓSIO NACIONAL DE FERMENTAÇÕES, 12., 1998, São Carlos. Anais... São Carlos: UFSCar, 1998.

DUARTE, M. C. T.; PELlEGRINO, A.C.A.; PORTUGAL, E. P.; PONEZI, A. N.; FRANCO, T.T. Characterization of alkaline xylanases from Bacillus pumilus. Brazilian Journal of Microbiology, v. 31, n. 2, p. 90-94, 2003.

DUKE, J. A.; VASQUEZ, R. Amazonian ethnobotanical dictionary. Florida: CRC Press, 1994. 
FERNANDES, E. A. Bioética e direitos humanos: A proteção da dignidade da pessoa humana face aos avanços da genética. 232f. Dissertação (Mestrado em Direitos Humanos). Faculdade de Direito, Universidade de São Paulo, São Paulo, 2008.

FISCHER, E.; THEISEN, I.; LOHMANN, L.G. Bignoniaceae. In: KADEREIT, J.W.; KUBITZKI, K. (Ed.). The families and genera of vascular plants. Flowering plants, dicotyledons: Lamiales (except Acanthaceae including Avicenniaceae). New York: Springer-Verlag, 2004.

FOGLIO, M.A. Um estudo químico da Artemisia annua L. aclimatada no Brasil 172 f. Tese (Doutorado em Ciências) - Instituto de Química, Universidade Estadual de Campinas, Campinas, 1996.

GOBBO-NETO, L.; LOPES, N. P. Principais fatores de influência no acúmulo de metabólitos secundários em plantas. Química Nova, p. 374-381, 2007.

GENTRY, A. H. A synopsis of Bignoniaceae ethnobotany and economic botany. Annals of the Missouri Botanical Garden, v. 79 p. 53-64, 1992.

GENTRY, A. H. Generic delimitations of Central American Bignoniaceae. Brittonia, v.25, p. 226-242, 1973.

GOTTLIEB, O. R.; KAPLAN, M. A.C.; BORIN, M.R. Biodiversidade, um enfoque químico-biológico. Rio de Janeiro: Editora da UFRJ, 1996.

HARBORNE, J. B.; WILLIAMS, C. A. Anthocyanins and other flavonoids. Natural Product Report, v. 18, p. 310-333, 2001.

HARBORNE, J.B. Comparative Biochemistry of the flavonoids - VI. Flavonoid Patterns in the Bignoniaceae and the Gesneriaceae. Phytochemistry, v. 6, p. 1643$1651,1967$.

HELLMANN, M. E. Tolerância ao congelamento e armazenamento de sementes de Caesalpinia echinata Lam. (pau-brasil). 88 f. Dissertação (Mestrado em Biodiversidade Vegetal e Meio Ambiente) - Instituto de Botânica, Secretaria do Meio Ambiente, São Paulo, 2006.

HSU, C. K.; LIAO, J.W.; CHUNG, Y.C.; HSIEH, C. P.; CHAN, Y.C. Xylooligosaccharides and fructooligosaccharides affect the intestinal microbiota and precancerous colonic lesion development in rats. Journal of Nutrition, v. 134, p.1523$1528,2004$.

JABOUR, F.F; SEIXAS, J.N.; TOKARNIA, C.H. Variation of the toxicity of Arrabidaea bilabiata (Bignoniaceae) in rabbits. Pesquisa Veterinaria Brasileira, v. 26, n. 3, p. 171-176, 2006.

JARBOE, L.R.; GRABAR, T.B.; YOMANO, L.P.; SHANMUGAN, K.T.; INGRAM, L.O. Development of Ethanologenic Bacteria. In: Advanced Biochemistry and

Biotechnology. Berlin: Springer-Verlag, 2007. v.108, p. 237-261. 
JIMÉNEZ-ESCRIG, A.; JIMÉNEZ-JIMÉNEZ, I.; SÁNCHEZ-MORENO, C.; SAURACALIXTO F. Evaluation of free radical scavenging of dietary carotenoids by the stable radical 2,2-diphenyl-1-picrylhydrazyl. Journal of the Science Food and Agriculture, v. 80, p. 1686-1690, 2000.

JORGE, M. P.; MADJAROF, C.; RUIZ, A.L.T.G.; FERNANDES, A.T.; RODRIGUES, R.A.F.; SOUZA, I.M.O.; FOGLIO, M.A.; CARVALHO, J.E. Evaluation of wound healing properties of Arrabidaea chica Verlot extract. Journal of Ethnopharmacology, v.118, p.361-366, 2008.

JULSING, M. K.; QUAX, W.J.; KAYSER, O. The Engineering of Medicinal Plants: Prospects and Limitations of Medicinal Plant Biotechnology. In: KAYSER, O.; QUAX, W. J. (Ed.). Medicinal Plant Biotechnology: From Basic Research to Industrial Applications. New York: Wiley-Vch Verlag, 2007. p. 24-26.

KALIL FILHO, A. N.; KALIL, G.P.C.; LUZ, A.I.R. Conservação de germoplasma de plantas aromáticas e medicinais da Amazônia brasileira para uso humano. Ministério da Agricultura e do Abastecimento: Comunicado Técnico. EMBRAPA, v.50, p. 1-4, 2000 .

KIM, D.H.; KIM, J.H.; BAE, S.I.; SEO, J.H.; OH, T.K.; LEE, C.H. Enhancement of natural pigment extraction using Bacillus species xylanases. Journal of Agricultural and Food Chemistry, v.53, p. 2541-2545, 2005.

KINGHORN, D. A. Pharmacognosy in the $21^{\text {st }}$ century. Journal of Pharmacy and Pharmacology, v. 53, p. 135-148, 2001.

KAYSER, O.; QUAX, W. J. Medicinal Plant Biotechnology: From Basic Research to Industrial Applications. Prefácio de JÖRG KNÄBLEIN. Weinheim: Wiley-Vch Verlag, 2007.

KOLENOVÁ, K.; VRSANAKÁ, M.; BIELY, P. Mode of action of endo- $\beta-1,4-$ xylanases of families 10 and 11 on acidic xylooligosaccharides. Journal of Biotechnology, v. 121, p. 338-345, 2006.

KONG, J. M.; KHANG, N. K.; CHIA L. S.; CHIA, T. F. Recent advances in traditional plant drugs and orchids. Acta Pharmacology Singapore, v. 24, n.1, p. 7-21, 2003.

LEHNINGER, A. L.; NELSON, D. L.; COX, M.M. Principles of Biochemistry. New York: W. H. Freeman, 2005.

LI, Y.; CUI, F.; LIU, Z.; XU, Y.; ZHAO, H. Improvement of xylanase production by Penicillium oxalicum ZH-30 using response surface methodology. Enzyme and Microbial Technology, v. 40, p. 1381-1388, 1927.

LOBO, A. M.; LOURENÇO, A. M. Biossíntese de produtos naturais. Lisboa: IST Pess, 2007.

LOHMANN, L.G.; HOPKINS, M.J.G. Bignoniaceae. In: RIBEIRO, J.E.L.S.; HOPKINS, M.J.G.; VICENTINI, A.; SOTHERS, C.A.; COSTA, M.A.S.; BRITO, J.M.; 
SOUZA, M.A.D.; MARTINS, L.H.P.; LOHMANN, L.G.; ASSUNÇÃO, P.A.C.L.; PEREIRA, E.C.; SILVA, C.F.; MESQUITA, M.R.; PROCÓPIO, L.C. (Org.). Flora da Reserva Ducke: Guia de identificação de uma floresta de terra-firme na Amazônia Central. Manaus: INPA-DFID, 1999. p. 608.

LOHMANN, L.G. Bignoniaceae. In: SMITH, N.; MORI, S.A.; HENDERSON, A.; STEVENSON, D.W.; HEALD, S.V. (Ed.). Flowering Plants of the Neotropics. New Jersey: Princeton University Press, 2004.

LOHMANN, L.G. Untangling the phylogeny of neotropical lianas (Bignonieae, Bignoniaceae). American Journal of Botany, v. 93, p. 304-318, 2006.

LOHMANN, L.G.; UllOA, C. Bignoniaceae. Plants Prototype Checklist. 2008. Disponível em: <www.iplants.org>. Acesso em: 28 out. 2008.

LOPEZ, M. J.; VARGAS-GARCIA, M. C.; SUÁREZ-ESTRELLA, F.; NICHOLS, N.N.; DIEN, B.S.; MORENO, J. Lignocellulose-degrading enzymes produced by the ascomycete Coniochaeta ligniaria and related species: Application for a lignocellulosic substrate treatment. Enzyme and Microbial Technology, v. 40, p. 794-800, 2007.

LORENZI, H.; MATOS, F.J.A. Plantas Medicinais no Brasil: nativas e exóticas cultivadas. Nova Odessa, São Paulo: Instituto Plantarum, 2002.

MALAJOVICH, M. A. Biotecnologia. Curitiba: Axcel Books, 2004.

MANDELS, M.; STENBERG, D. Recent Advances in Cellulase Technology. Journal of Fermentation Technology, v. 54, p. 267-286, 1976.

MARASCHI, M.; VERPOORTE, R. Engenharia do Metabolismo Secundário. Biotecnologia Ciência e Desenvolvimento, Brasília, v. 23, p. 24-28, 1999.

MAZZA, G.; MINIATI, E. Anthocyanins in fruits, vegetables, and grains. Boca Raton, Flórida: CRC Press, 1993.

MELO, M. J.; SOUZA, M.; PAROLA, A. J.; MELO, J. S. S.; CATARINO, F.; MARÇALO, J.; PINA, F. Identification of 7,4'-dyhydroxy-5-methoxyflavylium in "Dragon's Blood: To be or not to be an Anthocyanin. Chemistry European Journal, v. 13, p. 1417-1422, 2007.

MENSAHA.Y.; SAMPSON, J.; HOUGHTON, P. J.; HYLANDS, P.J.; WESTBROOK, J.; DUNN, M.; HUGHES, M.A.; CHERRY, G.W. Effects of Buddleja globosa leaf and its constituints relevant to wound healing. Journal of Ethnopharmacology, v. 77, p. 219-226, 2001.

MILLER, G. L. Use of dinitrosalicylic acid reagent for determination of reducing sugar. Analytical Chemistry, v. 31, p. 426-428, 1959.

MIR, L.; MOREIRA-FILHO, C. A.; MENCK, C. F. M.; SLUYS, M. A. V.; OLIVA, G.; VANNUCCHI, H.; RAW, I.; ZATS, M.; KALIL, J.; ARRUDA, P.; OLIVEIRA, S.; PENA, S. Genômica. São Paulo: Atheneu, 2004. 
MOSMANN, T. A rapid colorimetric assay for cellular proliferation and survival: application to proliferation and cytotoxicity assays. Journal of Immunological Methods, v. 65, p. 55-63, 1983.

MOREIRA, P. F. Estudo da dinâmica de equilíbrio ácido-base de antocianinas. 144 f. Tese (Doutorado em Ciências) - Instituto de Química, Universidade de São Paulo, São Paulo, 2003.

MOYER, R. A.; HUMMER, K. E.; FINN, C. E.; FREI, B., WROLSTAD, R. E. Anthocyanins, phenolics and antioxidant capacity in diverse small fruits: vaccinium, rubus and ribes. Journal of Agricultural and Food Chemistry, v. 50, p. 519-525, 2002.

NEWMAN, D. J; CRAGG, M.G. Natural products as sources of new drugs over the last 25 years. Journal of Natural Products, v. 70, p. 461-477, 2007.

NEWMAN, D. J. Natural products as leads to potential drugs: an old process or the new hope for drug discovery? Journal of Medicinal Chemistry, v. 51, n. 9, p. 2589-2599, 2008.

OLIVEIRA, P.A. Estudo da estabilidade e estabilização das antocianinas do bagaço de uva seibel 2. 98 f. Dissertação (Mestrado em Engenharia de Alimentos) - Faculdade de Engenharia de Alimentos, Universidade Estadual de Campinas, Campinas, 2001.

ORSKA-GAWRYS, J.; SUROWICE, I.; KEHL, J. REJNIAK, H. URBANIAKWALCZAK, K. ;TROJANOWITCZ, M. Identification of natural dyes in archeological Coptic textiles by liquid chromatography with diode array detection. Journal of Chromatography, v. 898, p. 239-248, 2003.

OVANDO-CHACÓN, S. L. ;WALISZEWSKI, K. N. Preparativos de celulasas comerciales y aplicaciones en procesos extractivos. Universidad Y Ciencia, v. 21, n. 42, p. 113-122, 2005.

PANCHATCHARAM, M.; MIRIYALA, S.; GAYATHRI, V. S.; SUGUNA, L. Curcumin improves wound healing by modulating collagen and decreasing reactive oxygens species. Molecular and Cellular Biochemistry, v. 290, p. 87-96, 2006.

PASCUAL-TERESA, S.; SANCHES-BALLESTA, M.T. Anthocyanins: from plant to health. Phytochemistry, v. 7, p. 281-299, 2008.

PAULETTI, P.M.; CASTRO-GAMBOA, I.; SILVA, D.H.S.; YOUNG, M.C.M.; TOMAZELA, D.M.; EBERLIN, M.N.; BOLZANI, V.S. New antioxidant CGlucosylxanthones from stems of Arrabidaea samydoides. Journal of Natural Products, v. 66, p. 1384-1387, 2003.

PESSOA, D. L. R.; CARTÁGENES, M. S.S.; BORGES, A.C. R.; BORGES, M. O. R.; MEDEIROS, I. A. Avaliação da administração crônica do extrato hidroalcoólico de Arrabidaea chica Verlot a ratos normotensos. SIMPÓSIO BRASILEIRO DE PLANTAS MEDICINAIS, 19., 2006, Salvador, 2006. Anais... São Paulo: Sociedade Brasileira de Plantas Medicinais. 
POORNA, C. A.; PREMA, P. Production and partial characterization of endoxylanase by Bacillus pumilus using agroindustrial residues. Biochemical Engineering Journal, v. 32, p. 106-112, 2006.

REZENDE, C.M.; CORREAA, V.F.S.; COSTA, A.V.M.; CASTRO, B.C.S. Constituintes químicos voláteis das flores e folhas do pau-brasil (Caesalpinia echinata Lam.). Química Nova, v. 27, n.3, p. 414-416, 2004.

SAVIRANTA, N.M.; ANTTONEN, M.J.; VON WRIGHT, A.; KARJALAINEN, R. O. Red clover (Trifolium pretense L.) isoflavones: determination of concentrations by plant stage, flower colour, plant part and cultivar. Journal of the Science of Food and Agriculture, v. 88, p. 125-132, 2008.

SCHIOZER, A. L.; SILVA, J. C. T.; PEREIRA, R.; BARATA, L. E. S. Extrações de desoxiantocianidinas do Carajiru (Arrabidaea chica). In: SIMPÓSIO BRASILEIRO DE PLANTAS MEDICINAIS, 19., 2006, Salvador, 2006. Anais... São Paulo: Sociedade Brasileira de Plantas Medicinais.

SCOGIN, R. Anthocyanins of the Bignoniaceae. Biochemical and Sistematics Ecology, v. 8, p. 273-276, 1980.

SILVA, A.C.R. New perspectives for Agricultural Biotechnology in Brazil. In: MEETING OF THE NATIONAL AGRICULTURAL BIOTECHNOLOGY COUNCIL, 2006. Abstracts... Disponível em: <http://nabc.cals.cornell.edu/pubs/nabc_18/NABC18 _DaSilva.pdf>. Acesso em: 17 Jul. 2007.

SILVA, A. C.; GILBERT, B. VIAL CORRÊA, C. B.; CAVALEIRO, M. V. S.; DOS SANTOS, R.R.; TOMASSINI, T. Biodiversidade: Perspectitivas e Oportunidades Tecnológicas. Fitoterápicos, FIOCRUZ, 2006.

SIMÕES, C. M. O.; SCHENKEL, E. P.; GOSMANN, G.; MELLO, J. C. P.; MENTZ, L. A.; PETROVICK, P. R. Farmacognosia: da planta ao medicamento. Florianópolis: Editora da UFSC; Porto Alegre: Editora da UFRGS, 2007.

SKEHAN, P.; STORENG, R.; SCUDIERO, D.; MONKS, A.; MCMAHON, J.; VISTICA, D.; WARREN, J. T.; BOKESCH, H.; KENNEY, S.; BOYD, M. R. New colorimetric cytotoxicity assay for anticancer-drug screening. Journal of National Cancer Institute, v.82, p. 1107-1118, 1990.

SMITH, J.E. Biotechnology. Cambridge: Cambridge University Press, 2004.

SPANGLER, R.E.; OLMSTEAD, R.G. Phylogenetic analysis of Bignoniaceae based on the cpDNA gene sequences $r b c \mathrm{~L}$ and $n d h \mathrm{~F}$. Annals of the Missouri Botanical Garden, v. 86, p. 33-46, 1999.

SRIVASTAVA, A.; AKOH, C.C.; FISCHER, J.; KREWER, G. Effect of anthocyanin fractions from selected cultivars of Georgia - grown blueberries on apoptosis and phase II enzymes. Journal of Agricultural and Food Chemistry, v. 55, p. 3180-3185, 2007.

TAIZ, L.; ZEIGER, E. Plant Physiology. Massachusetts: Sinauer Associates, 2004. 
TAKEMURA, O. S.; IINUMA, M.; TOSA, H.; MIGUEL, O. G.; MOREIRA, E. A.; NOZAWA, Y. A flavone from leaves of Arrabidaea chica f. Cuprea. Phytochemistry, v. 38, p. 1299-1300, 1995.

VALKO, M.; LEIBFRITZ, D.; MONCOL, J.; CRONIN, M.T.D.; MAZUR, M. TELSER, J. Free radicals and antioxidants in normal physiological functions and human disease. International Journal of Biochemistry and Cell Biology, v. 38, p. 44-84, 2007.

VALLE, M.G.; ASSAD, A. L. D. Sistema Nacional de Inovação em Biotecnologia: Recentes Mudanças. Fitos Pesquisa, Desenvolvimento e Inovação em Fitoterápicos, v. 3, n. 1, p. 6-19, 2007.

VERPOORTE, R.; CHOI, Y.H.; KIM, H. K. Ethnopharmacology and systems biology: A perfect holistic match. Journal of Ethnopharmacology, v. 100, p. 53-56, 2005.

VERPOORTE, R.; KIM, H. K.; CHOI, Y. H. Metabolomics. In: KAYSER, O.; QUAX, W. J. Medicinal Plant Biotechnology: From Basic Research to Industrial Applications. Weinheim: Wiley-Vch Verlag, 2007. p. 9-11.

VON POSER, G.L.; SCHRIPSEMA, J.; HENRIQUES, A.T.; JENSEN, S.R. The distribution of iridoids in Bignoniaceae. Biochemistry Systems Ecology, v. 28, p. 351$366,2000$.

WEI, Q.-K.; CHEN, T.-R.; CHEN, J.-T. Use of Bacillus subtilis to enrich isoflavone aglycones in fermented natto. Journal of the Science of Food and Agriculture, v. 88, p. 1007-1011, 2008.

WEN, D.; LI, C.; DI, H.; LIAO, Y.; LIU, H. A universal HPLC method for determination of phenolic acids in compound herbal medicines. American Chemical Society, v. 53, n. 17, p. 6.624-6.629, 2005.

WILLIAMS, C.A.; RAYER, R.J. Review Anthocyanins and other flavonoids. Natural Product Reports, v. 21, n. 4, p. 539-573, 2004.

WALSH, G. Biopharmaceuticals, Biochemistry and Biotechnology. 2. ed. Ireland: Wiley, 2003.

ZAFRA-STONE, S.; YASMIN, T.; BAGCHI, M. Berry anthocyanins as novel antioxidants in human health and disease prevention. Molecular Nutrition \& Food Research, v. 51, n. 6, p. 675-683, 2007.

ZORN, B.; GARCIA-PIÑERES, A. J.; CASTRO, V.; MURILlO, R.; MORA, G.; MERFORT, I. 3-Desoxyanthocyanidins from Arrabidaea chica. Phytochemistry, v. 56, p. 831-835, 2001. 